\title{
STEREODIRECTING EFFECT OF CYCLIC SILYL PROTECTING GROUPS IN CHEMICAL GLYCOSYLATION
}

\author{
Nahoko Yagami, Akihiro Imamura ${ }^{1}$ \\ ${ }^{1}$ Department of Applied Bio-organic Chemistry, Faculty of Applied Biological Sciences, Gifu University, 1-1 Yanagido, Gifucity 501-1193, Japan
}

\section{ABSTRACT}

Glycosyl donors with cyclic silyl protecting groups, such as di-tert-butylsilylene (DTBS) and tetraisopropyldisiloxanylidene (TIPDS) groups, have been found to affect the stereoselectivity of diverse chemical glycosylations. Moreover, the effects of ringrestriction for stereoselective glycosylations have provided new insights into the reaction mechanism of chemical glycosylation. We present a historical overview of stereoselective glycosylations using such ring-restricted glycosyl donors and their applications to the synthesis of biologically relevant carbohydrate molecules.

Keywords: Carbohydrate, Cyclic protection, Glycosylation, Organic synthesis, Protecting group, Stereoselectivity

\section{Introduction}

In the field of carbohydrate chemistry, a large number of useful stereoselective glycosylation methods that control the stereochemistry of the newly formed glycosylated products in chemical glycosylation have been developed. For example, neighboring group participation by acyl protecting groups is useful for the synthesis of 1,2-trans glycosides, while solvent effect and the intramolecular aglycone delivery method have been utilized for 1,2-cis glycosides. In recent years, several stereoselective glycosylation methods using glycosyl donors ring-restricted by cyclic silyl protecting groups such as di-tertbutylsilylene (DTBS) and tetraisopropyldisiloxanylidene (TIPDS) groups have been developed. Many experiments have demonstrated the applicability of cyclic silyl protecting groups as a stereocontrolling element in chemical glycosylation. Furthermore, such methodology has led to the efficient synthesis of a large number of biologically relevant carbohydrates. We present an overview of stereoselective glycosylations with silyl protecting group-tethered bicyclic glycosyl donors here.

\section{DTBS-directed stereoselective glycosylation \\ 2.1. $\alpha$-Galactosides/Galactosaminides}

DTBS-directed stereoselective glycosylation was first developed in the formation of $\alpha$-galactosides and $\alpha$-galactosaminides (Imamura et al., 2003). The potential of the

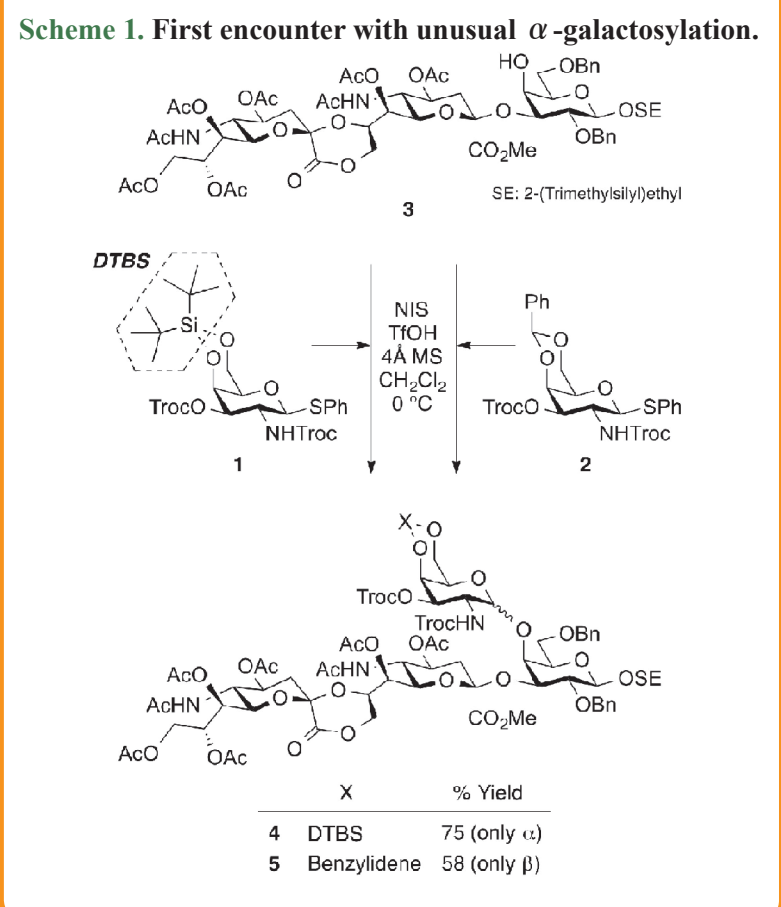


DTBS group as an $\alpha$-galactosylation enhancer was discovered by chance during a synthetic study on b-series gangliosides, in which 4,6-O-DTBS-protected galactosaminyl (GalN) donor $\mathbf{1}$, used as a surrogate of 4,6-O-benzylidene-protected donor $\mathbf{2}$, exhibited $\alpha$-selectivity in the glycosylation with trisaccharide acceptor $\mathbf{3}$ to afford tetrasaccharide 4 , despite the presence of the neighboring Troc group on the $\mathrm{C}-2$ amino functionality. Conversely, the corresponding 4,6-O-benzylidenated donor 2 gave $\beta$-glycosyl product 5 exclusively (Scheme 1). Notably, this unexpected stereoselectivity was observed under reaction conditions with a wide variety of leaving groups, promoter systems, reaction temperatures, solvent systems, and protecting groups (even in the presence of a neighboring acyl group at C-2) (Imamura et al., 2006; 2008a; 2008b). High $\alpha$-selectivity was almost completely independent of the nucleophile (the sugar acceptor), which could be an alcohol (either linear or sterically hindered), a phenol, Ser, Thr, and partially protected monosaccharides (Fig. 1). Only reversal selectivity was observed when the glycosylation was performed with a glycosyl bromide donor in the presence of insoluble silver silicate as a promoter.

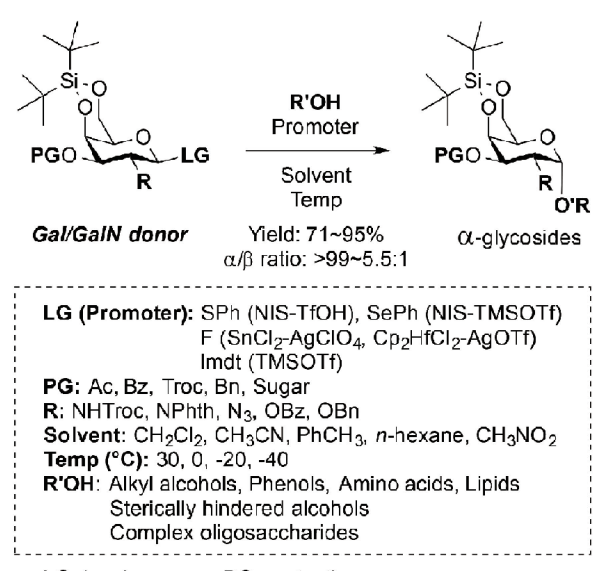

LG: leaving group, $P G$ : protecting group

Fig.1: Outline of DTBS-directed $\alpha$-galactosylation. LG: leaving group, PG: protecting group.

The origin of the prominent $\quad \alpha$-selectivity in DTBS-directed $\alpha$-galactosylation has been elucidated by a combination of experimental and computational studies (Imamura et al., 2016). Glycosidation experiments using various GalN donors, which differed in terms of only the protecting group at the $\mathrm{C} 4$ and $\mathrm{C} 6$ positions, demonstrated that the presence of the DTBS group is essential for strong $\alpha$-selectivity. For example, even the use of a diisopropylsilylene-type donor very similar to the DTBS donor diminished the $\alpha$-selectivity. Furthermore, an examination of the geometry of oxocarbenium intermediates postulated by density functional theory (DFT) calculations was performed. The DFToptimized geometry of the oxocarbenium intermediate formed from phenyl 3-O-acetyl-2-deoxy-4,6-O-di-tert-butylsilylene-2phthalimide-1-thio- $\beta$-D-galactoside revealed that the sugar ring with the DTBS group at the $\mathrm{C} 4$ and $\mathrm{C} 6$ positions adopts the ${ }^{4} \mathrm{H}_{3}$ conformation. Furthermore, calculations of Mulliken and natural charges on atoms in selected glycosyl donors to estimate the electronegativity of oxygen atoms at $\mathrm{C} 4$ and $\mathrm{C} 6$ revealed that oxygen atoms next to a silicon atom have a higher electron density compared with that of oxygen atoms next to carbon atoms. This result indicates the strong stabilization of the oxocarbenium ion by axially oriented $\mathrm{O} 4$ and/or O6 (through-space electron donation) (Miljkovic et al., 1997) could occur, leading to the bulky tert-butyl substituent on $\mathrm{O} 4$ and/or O6 being positioned closer to the anomeric center. The fact that the DTBS-protected donors can be activated promptly during the course of glycosylation reactions supports the strong stabilization of the oxocarbenium intermediates.

Taken together the experimental and the computational results, the reaction mechanism for the DTBS-directed $\alpha$-galactosylation shown in Fig. 2 was proposed. Upon activation of the glycosyl donor $\mathbf{6}$, the corresponding oxocarbenium intermediate 7 is generated. Here the conformational freedom of the sugar ring is limited to the half-chair ${ }^{4} \mathrm{H}_{3}$ conformer because other conformers are unattainable owing to the fused ring system formed by the DTBS group. The ${ }^{4} H_{3}$ conformer can then undergo nucleophilic attack by the alcohol acceptor, predominantly from the exo side ( $\alpha$-face) because endo attack on the $\beta$-face is blocked by the substantial steric hindrance of the tert-butyl group. Endo attack and exo attack generate the distinct "exploded" transition states. Next, the respective transition states can access a twist-boat-like conformer $\mathbf{8}$ (generated from endo attack) and a chair-like conformer 9 (generated from exo attack), respectively, to maximize orbital overlap between the approaching alcohol acceptor and the developing lone pair on oxygen, resulting in glycosidated products where the resulting $\mathrm{sp}^{3}$-hybridized orbitals are anti-coplanar. The chair-like conformer $\mathbf{9}$ is more stable than $\mathbf{8}$, which is in a kinetically disfavored twist-boat-like conformation that must undergo a ring-flip to reach the more stable equatorial $\beta$-product 10. Moreover, $\mathbf{8}$ clearly suffers from unfavorable steric clash between the tert-butyl substituent and the incoming alcohol acceptor. Hence, nucleophilic attack predominantly occurs via the pathway leading to the $\alpha$-product 11. These studies have demonstrated that the preferential formation of the ${ }^{4} H_{3}$ oxocarbenium intermediate and subsequent access to the kinetically stable chair-like transition state can provide high stereoselectivity. Indeed, the powerful steric effect of the bulky DTBS group is the most important factor in the observed $\alpha$-selectivity.

To date, DTBS-directed $\alpha$-galactosylation has been applied to the syntheses of various $\alpha$-GalNAc/Gal-containing glycans, 
Fig.2: Proposed mechanism of DTBS-directed $\alpha$-galactosylation.



Fig.3: Structurally complex natural products synthesized via DTBS-directed $\alpha$-galactosylation.

such as $\alpha$-GalNAc-Ser/Thr ( $O$-glycan core) (Imamura et al., 2006), $\alpha$-galactosyl ceramides (Kimura et al., 2006; Lee et al., 2006), isoglobotrihexosylceramide (Kimura et al., 2006), the $\alpha$-tetrasaccharyl-Ser segment of glycophorin A (Imamura et al., 2006), $p$-nitrophenyl $O$-glycan cores (Sato et al., 2009), 4-methylumbelliferyl T-antigen (Imamura et al., 2005), human
ABO histo-blood group antigens (Hara et al., 2014), mammalian gangliosides (Komori et al., 2008), and other natural products. Furthermore, this methodology was shown to be effective for the construction of structurally complex natural products including echinodermatous gangliosides PNG-2A (12) (Goto et al., 2015) and GP-3 (13) (Goto et al., 2016) as well as the inner- 
core oligosaccharide $\mathbf{1 4}$ of the lipopolysaccharide of Francisella tularensis that causes tularemia (Boltje et al., 2012) (Fig. 3). Very recently, synthesis of the Staphylococcus aureus strain $\mathrm{M}$ capsular polysaccharide repeating unit $\mathbf{1 5}$ was successfully accomplished via DTBS-directed $\alpha$-galactosylation with the phenylselenoglycoside $\mathrm{GalN}_{3}$ donor $\mathbf{1 6}$ that is readily activated using the $\mathrm{Ph}_{2} \mathrm{SO} / \mathrm{Tf}_{2} \mathrm{O}$ system. Hagen et al. (2017) investigated the stereochemical influence of a $\mathrm{C} 2$-azido group in this system and potential reactive intermediates for the first time. Thus, preactivated $\mathbf{1 6}$ leads to the clean formation of a new species that, on the basis of its chemical shift and $J_{\mathrm{H} 1, \mathrm{H} 2}$-coupling, is likely triflate $\mathbf{1 7}$. Intermediate $\mathbf{1 8}$ proved to be more stable than the triflate 17. Subsequent glycosylation examination with a set of acceptors revealed that the corresponding $\alpha$-galactosides 20 are obtained preferentially $(\alpha / \beta$ ratio $=>19: 1)$, which was in accordance with previously obtained results. Furthermore, even though the DTBS donor had been completely transformed into the corresponding $\alpha$-triflate $\mathbf{1 7}$, and ethanol and cyclohexanol are nucleophilic enough to engage in $\mathrm{S}_{\mathrm{N}} 2$-type glycosylation reactions, no direct displacement of the anomeric triflate leading to $\beta$-product 19 was observed (Fig. 4). The authors concluded that the selectivity obtained, with the preactivation conditions used, attested to the extremely powerful stereodirecting effect of the DTBS group, and that the pathway followed by these galactosylations probably follows an attack of the nucleophiles on the $\alpha$-face of an ${ }^{4} \mathrm{H}_{3}$-oxocarbenium ion-like intermediate.

Similar to 4,6-DTBS-tethered Gal donors, 3,6-tethering is also found to be $\alpha$-directing. Pedersen et al. have demonstrated that the 3,6-DTBS-tethered galactosyl thioglycoside donor 21, which adopts approximate $B_{1,4}$ conformations in the ground state, is highly reactive (super armed) compared to conventionally armed glycosyl donors and affords the $\alpha$-glycosylated product with a high degree of stereoselectivity (Heuckendorff et al., 2013). Conversely, when the corresponding galactosyl fluoride $\mathbf{2 2}$ is glycosidated with acceptors 23-25 in the presence of $\mathrm{SnCl}_{2}$ and $\mathrm{AgB}\left(\mathrm{C}_{6} \mathrm{~F}_{5}\right)_{4}$ in benzotrifluoride (BTF) as the solvent, $\beta$-selectivity is observed (Table 1 ). This reversal of stereoselectivity would attribute to the thermodynamic equilibrium between glycosylated anomers after glycosylation, where the $\beta$-anomer becomes thermodynamically more stable due to restriction by the 3,6-bridge. Furthermore, the first investigations into glycosyl fluoride donors having a 3,6-tethered (3,6-O-oxylylene) as the $\beta$-directing factor and the post-glycosylation anomerization under the $\mathrm{SnCl}_{2} / \mathrm{AgB}\left(\mathrm{C}_{6} \mathrm{~F}_{5}\right)_{4}$ promoter system have been reported by Okada et al., (2012).

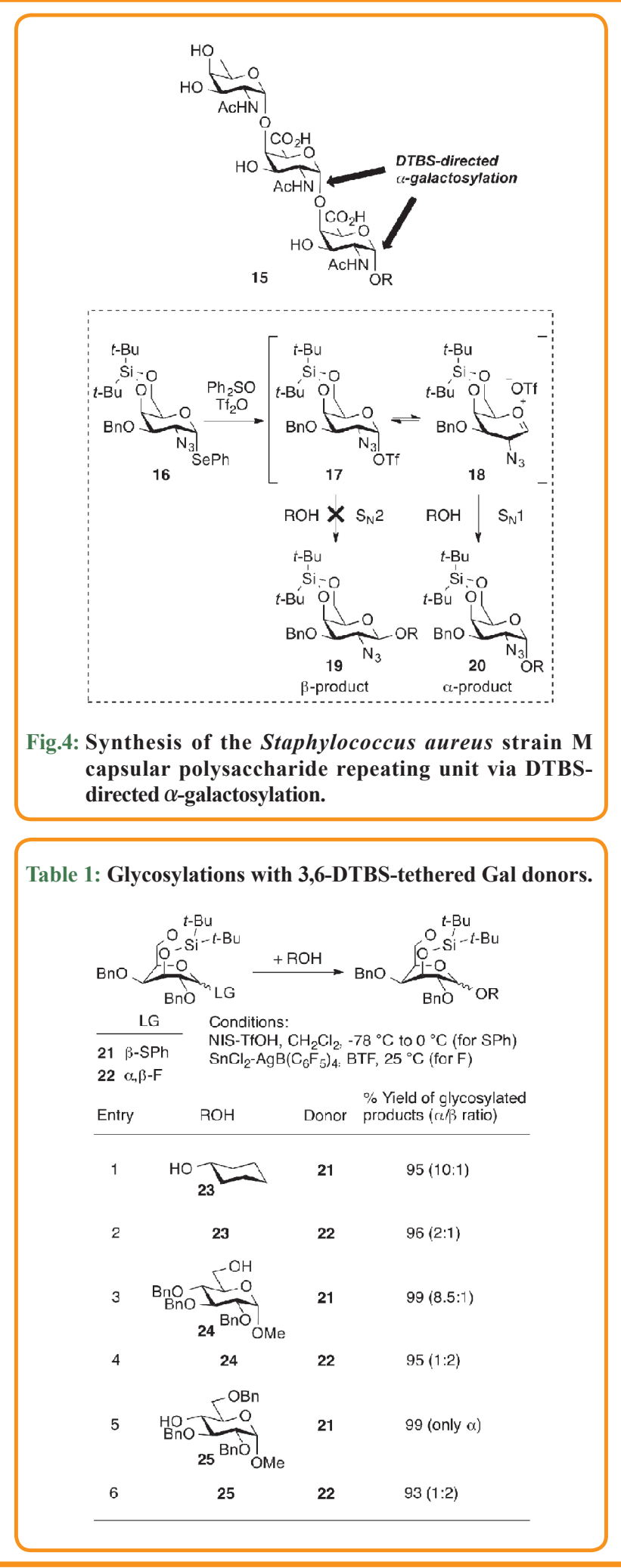


Please cite this article as

Yagami and Imamura, Reviews in Agricultural Science, 6: 1-20, 2018

http://dx.doi.org/10.7831/ras.6.1

\section{2. $\beta$-Arabinofuranosides}

The construction of 1,2-cis-furanosides, such as $\beta$-arabinofuranosides and $\alpha$-galactofuranosides, is generally more difficult than that of 1,2-cis-pyranosides because the magnitude of the anomeric effect in furanosides is reduced by the ease of pseudorotation attributed to the high flexibility of furanose rings. Thus, methods for reliable stereoselective synthesis of 1,2-cis-furanosides are limited. As a successful example, Lowary's group (Gadikota et al., 2001; 2003) succeeded in the introduction of $\beta$-arabinofuranosides by indirect protocols with a 2,3-anhydrofuranosyl donor. Zhu et al. (2006) reported the direct stereoselective $\beta$-L-arabinofuranosylation with 3,5-O-DTBSprotected L-arabinofuranosyl donor 26 (Zhu et al., 2006). A range of glycosidations of $\mathbf{2 6}$ with various glycosyl acceptors including primary (27) and secondary alcohols give the corresponding $\beta$-glycosylated products predominantly. The high $\beta$-selectivity may be interpreted as follows: The oxocarbenium intermediate formed from 26 predominantly adopts the $E_{3}$ conformer 29 due to locking of the sugar ring by the DTBS group, in which nucleophilic attack from the $\alpha$-face is hampered due to unfavorable eclipsing interactions with $\mathrm{H}-2$, and thus $\beta$-face attack is preferred (Fig. 5). Another type L-arabinofuranosyl donor 30, which possesses the trichloroacetimidate group as the leaving group, also provides high $\beta$-selectivity $(85 \%, \alpha / \beta<1: 10$ or $92 \%$, only $\beta$ ) and has been applied to the synthesis of hexasaccharide 31 and related fragments of rhamnogalacturonan II, a highly complex pectic oligosaccharide found in the primary cell walls of higher plants (Rao and Boons, 2007) (Fig. 6).

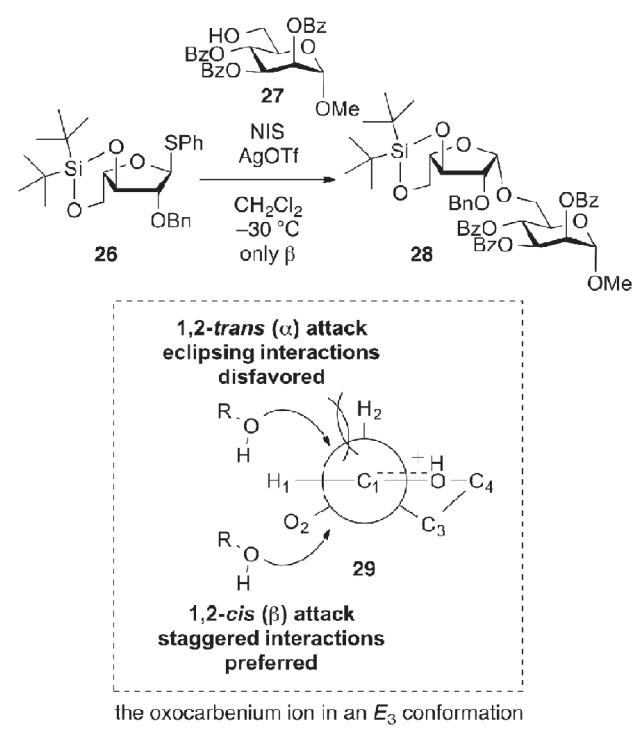

Fig.5: An example of DTBS-directed $\beta$-L-arabinofuranosylation.

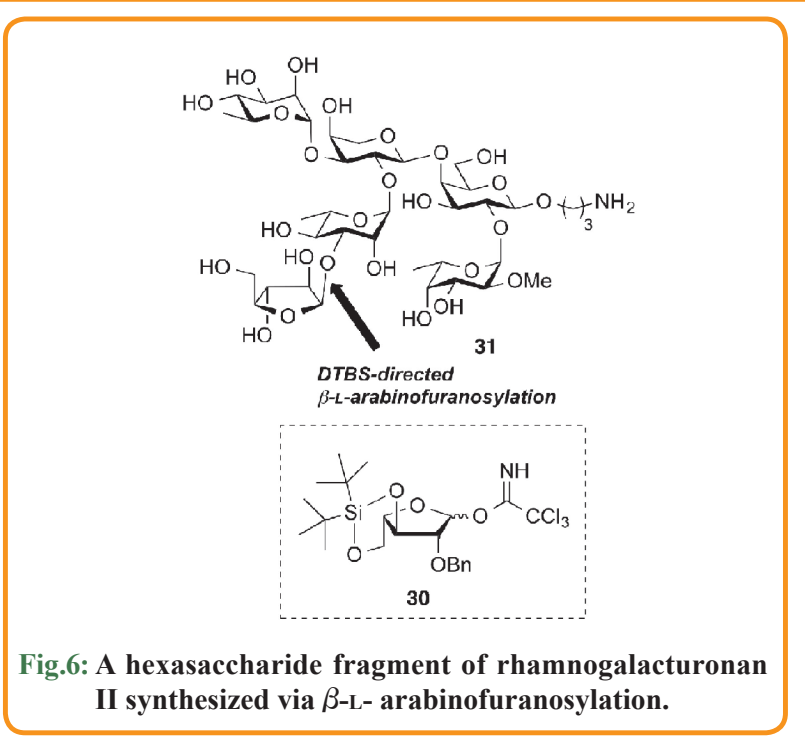

Zhu, a co-author of the above-mentioned $\beta$-selective L-arabinofuranosylation report (Zhu et al., 2006), and colleagues (Wang et al., 2008) have applied the same methodology for the synthesis of enantiomeric D-arabinofuranoside. Though DTBS-protected D-arabinofuranosyl donors activated by the $\mathrm{N}$-iodosuccinimide (NIS)/silver trifluoromethanesulfonate (AgOTf) system give good $\beta$-selectivity as expected, it is noteworthy that overall the selectivities are lower than those obtained in L-arabinofuranosylation.

Crich et al. (2007) discovered the importance of the activation system on the stereoselectivity in arabinofuranosylation during glycosylation experiments using both D- and L-arabinofuranosyl donors. High $\beta$-selectivities were obtained when the L-arabinofuranosyl donors were activated using the NIS/ AgOTf system for the thioglycoside donor $\mathbf{3 2}$ or $\mathrm{Tf}_{2} \mathrm{O}$ for the sulfoxide donor 33, while the glycosylations mediated by the 1-benzenesulfinyl piperidine (BSP)/ $\mathrm{Tf}_{2} \mathrm{O}$ or $\mathrm{Ph}_{2} \mathrm{SO} / \mathrm{Tf}_{2} \mathrm{O}$ afforded the corresponding anomeric mixtures with little or no selectivity (Table 2). A plausible interpretation for the poor stereoselectivity observed in the BSP method is that it is due to the generation of various glycosylating species arising from incomplete conversion of the thioglycoside to the corresponding glycosyl triflate. 


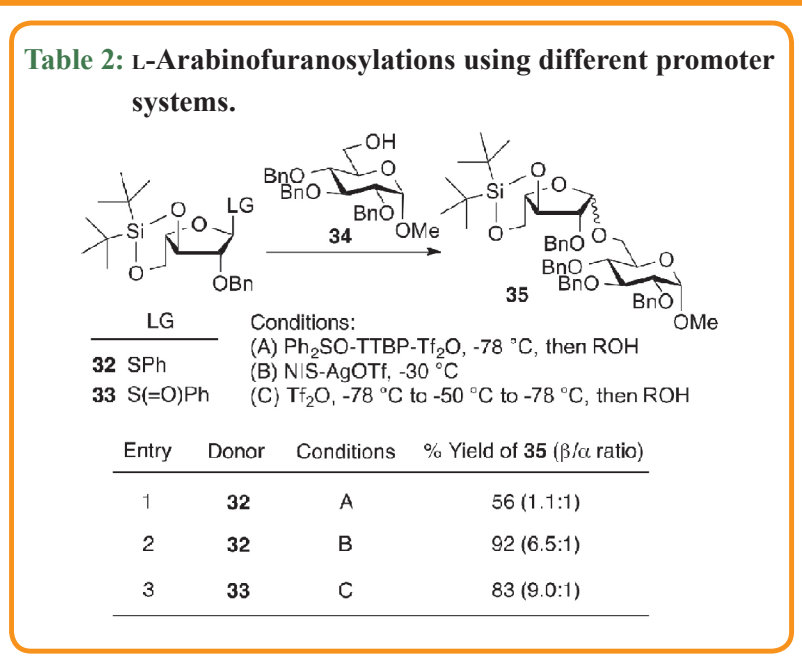

The development of DTBS-tethered arabinofuranosyl donors allowed the synthesis of a fragment of arabinogalactan, which is a polysaccharide containing arabinofuranose residues found in the cell walls of mycobacteria including Mycobacterium tuberculosis. Lowary's group (Joe et al., 2007) has successfully achieved the synthesis of the docosanasaccharide arabinan domain 36, which contains four $\beta$-D-Ara $f$ residues, in a highly convergent manner

(Fig. 7).

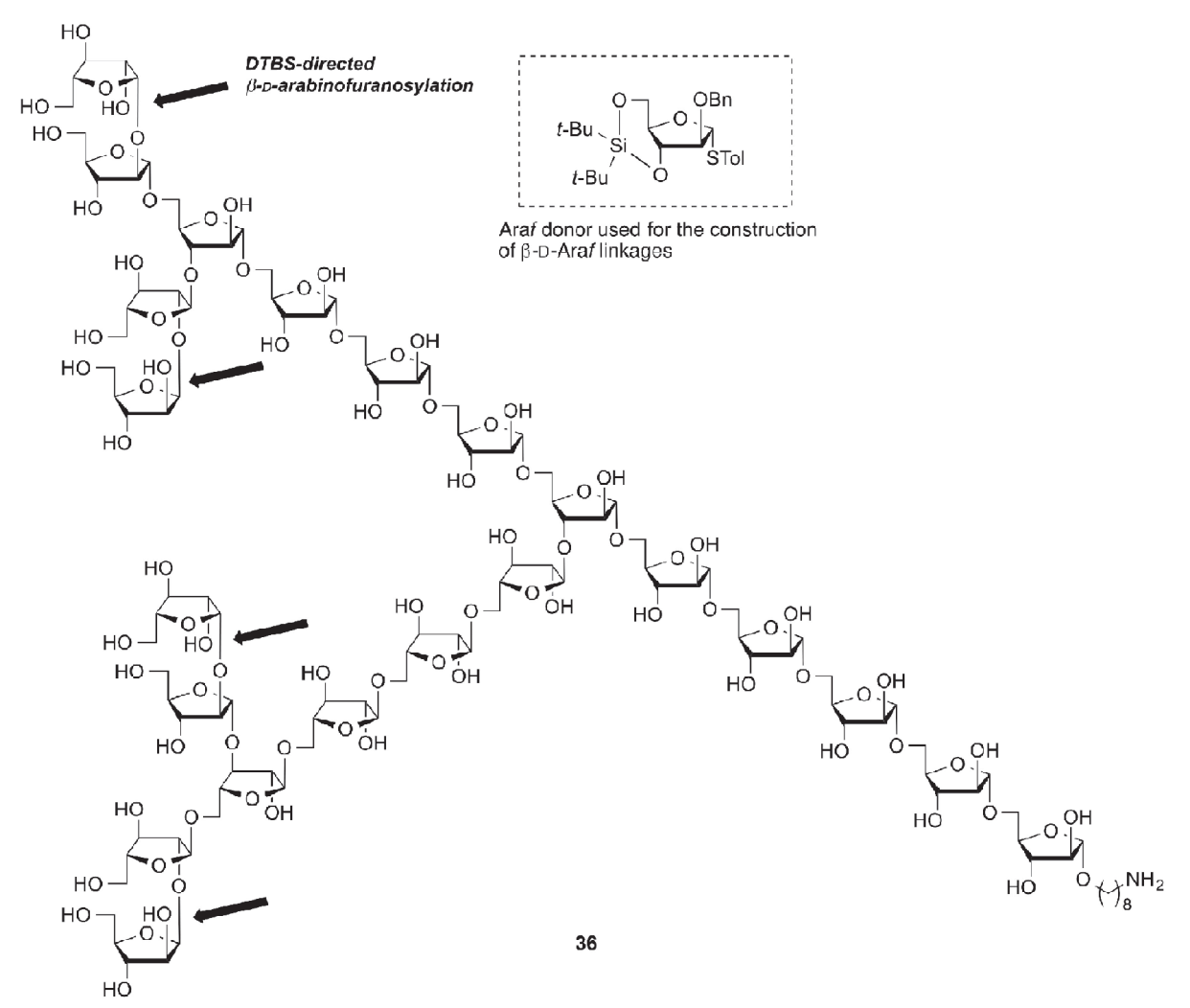

Fig.7: Structure of the docosanasaccharide arabinan domain with four $\beta$-D-Ara $f$ residues. 
Please cite this article as

Yagami and Imamura, Reviews in Agricultural Science, 6: 1-20, 2018

http://dx.doi.org/10.7831/ras.6.1

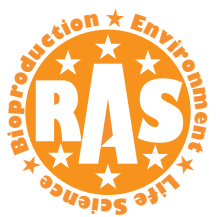

\section{3. $\alpha$-Galactofuranosides}

Galactofuranose (Galf)-containing oligosaccharides have attracted much attention since the Gal $f$ residue is found in many pathogenic microorganisms. Although Gal $f$ is commonly found in the $\beta$-configuration, several examples of $\alpha$-D-Galf-containing oligosaccharides with 1,2-cis-configuration have been observed in both bacteria and fungi. However, the chemical construction of 1,2-cis $\alpha$-D-Gal $f$ linkages is more difficult to achieve than that of 1,2-trans $\beta$-D-Gal $f$ linkages, which are readily obtained through neighboring group participation, and no general method is available for this purpose. Tilve and Gallo-Rodriguez (2011) reported the stereochemical construction of 1,2-cis $\alpha$-D-Galf linkages employing 3,5-O-DTBS-protected D-galactofuranosyl donors, the strategy for which exploited the stereochemical relationship between L-arabinofuranose and D-galactofuranose (Fig. 8). In light of the stereodirecting effect of the DTBS protection in arabinofuranosylation, it was speculated that the 3,5-DTBS protecting group on galactofuranosyl oxocarbenium intermediates $\mathbf{3 7}$ would favor the access of the nucleophile from the "inside" face ( $\alpha$-face) of the rigid conformer, avoiding the eclipsing interactions produced by $\beta$-face approach (Fig. 9). Consequently, it was found that, in the glycosylation with the Gal $f$ trichloroacetimidate donor, reaction temperature and solvents significantly affect the stereochemical outcome. Higher $\alpha$-selectivities are obtained at $-78{ }^{\circ} \mathrm{C}$ in diethyl ether (or THF) as solvent, while almost no selectivities are observed in $\mathrm{CH}_{2} \mathrm{Cl}_{2}$ (Table $3)$. It can be speculated that the $\alpha$-stereoselectivities observed in ether-type solvents are due to that fact that ethereal solvents can approach from the $\beta$-face of the oxocarbenium intermediates to form the coordinate bond and then be displaced by the acceptor alcohols, leading to the $\alpha$-product.

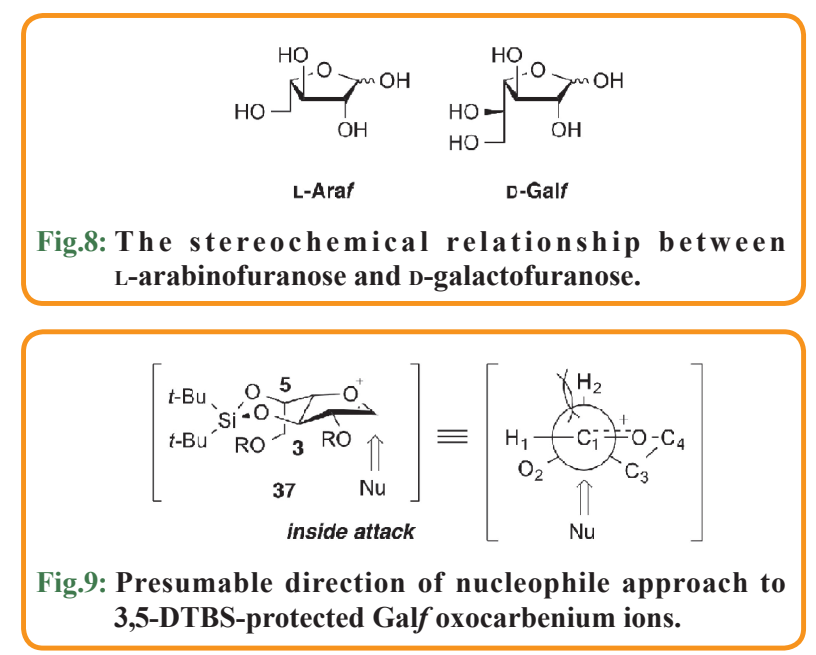

6-O-substitution on the constrained donor is also found to influence the stereoselectivities. Higher $\alpha$-selectivity is obtained with a 6-O-acetyl-protected donor rather than the 6-O-benzyl analog, which excludes the remote participation exerted by an acyl group at O-6 (Table 3). It has been suggested that a stereoelectronic effect owing to the presence of an electronwithdrawing group is involved, even though the detailed mechanism is still unknown and requires further study.



Subsequently, Tilve and Gallo-Rodriguez (2014) had examined the application of 3,5-O-DTBS-protected D-galactofuranosyl thioglycoside donors for stereoselective 1,2-cis $\alpha$-D-galactofuranosylation, in which the influence of the reaction solvent, temperature, and activating system was evaluated (Tilve and Gallo-Rodriguez, 2014). Interestingly, in contrast to the use of the trichloroacetimidate donor, $\alpha$-selectivity is obtained when the corresponding thioglycoside donor is activated using the $p-\mathrm{NO}_{2} \mathrm{PhSCl} / \mathrm{AgOTf}$ system in $\mathrm{CH}_{2} \mathrm{Cl}_{2}$ rather than in diethyl ether, regardless of the reaction temperature (Table 3 ). However, no explanation regarding the different stereochemical outcomes in different reaction solvents observed between the trichloroacetimidate donor and thioglycoside donor was provided.

Complete $\alpha$-selectivity was obtained in the construction of $\alpha$-D-Galf-(1,6)-D-Man disaccharide $\mathbf{4 3}$, a motif present in the cell wall polysaccharide of the dimorphic fungus Paracoccidioides brasiliensis that is the causative agent of paracoccidioidomycosis (Scheme 2). This was the first report of a complete 
diastereoselective synthesis of an $\alpha$-D-Galf-(1,6)-D-Man linkage.

Scheme 2. Complete $\alpha$-selective synthesis of an $\alpha$-D-Galf(1,6)-D-Man disaccharide motif.

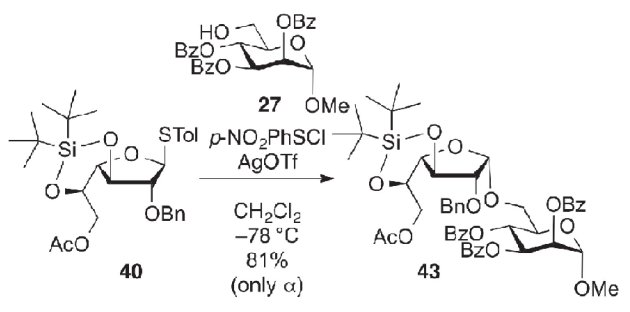

\section{4. $\beta$-Glucosides}

Heuckendorff et al., (2013) reported that the glucosyl fluoride donor $\mathbf{4 4}$ by 3,6-O-DTBS-tethering into a ${ }^{3} S_{1}$ conformation is highly reactive (super armed), and complete $\beta$-selectivity in the coupling with glycosyl acceptors 23-25 was observed with the promoter system $\mathrm{SnCl}_{2} / \mathrm{AgB}\left(\mathrm{C}_{6} \mathrm{~F}_{5}\right)_{4}$ in BTF. Notably, in this glycosylation the $\alpha$-anomer is initially formed but in time is anomerized to the thermodynamically more stable $\beta$-anomer. The post-glycosylation anomerization presumably takes place because of both the 3,6-bridged donor conformation and catalysis performed by HF formed under the reaction conditions. In contrast, when the corresponding thioglycoside 45 is used as the donor in the NIS/TfOH-promoted glycosylation, all glycosylations are slightly $\alpha$-selective (Table 4).

Complete $\beta$-selectivity is also observed when 3,6-DTBS-bridged 2-azido glucosaminyl fluoride donor $\mathbf{4 7}$ is glycosidated with a simple alcohol such as $\mathbf{2 3}$. The selectivity however decreases when using the glycosyl acceptors $\mathbf{2 4}$ and $\mathbf{2 5}$. Conversely, the $\alpha$-selectivity using the corresponding thioglycoside donor $\mathbf{4 8}$ is the same as that of glucose derivatives (Table 5).

A competition glycosylation experiment performed between 45 and the classic super armed donor $\mathbf{4 9}$, which resembles a boat conformation, resulted in more of the bridged donor $\mathbf{4 5}$ being consumed, suggesting that DTBS-bridged donors are more reactive than the classic super armed donors (Fig. 10).
Table 4: Glycosylations with 3,6-DTBS-tethered Glc donors.
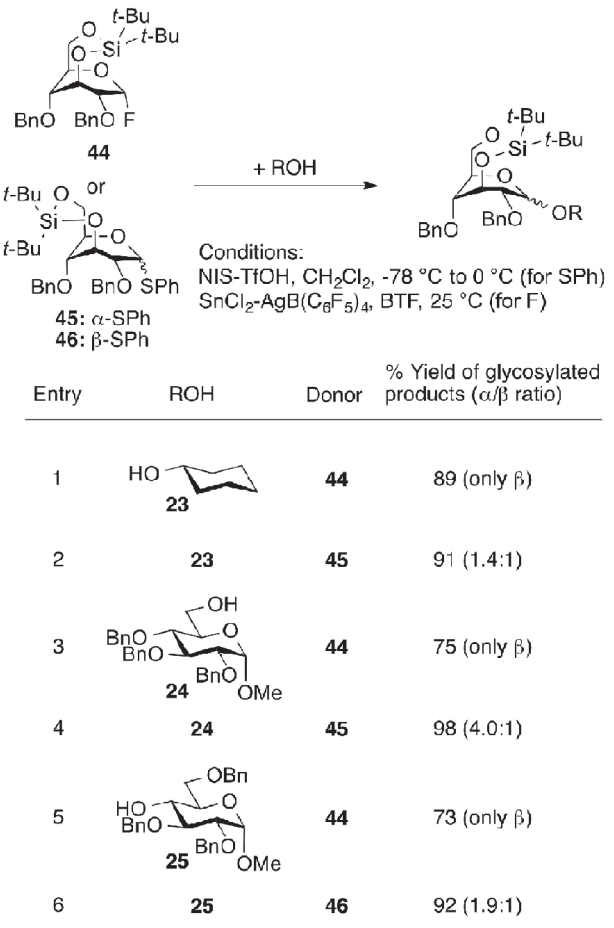

Table 5: Glycosylations with 3,6-DTBS-tethered 2- $\mathrm{N}_{3}$ glucosaminyl donors.

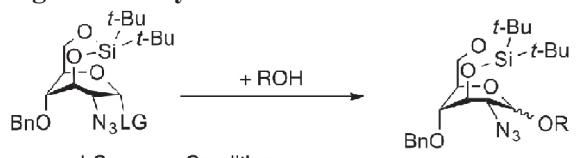

\begin{tabular}{ll} 
LG & Conditions: \\
\hline $47 \alpha-\mathrm{F}$ & $\quad \mathrm{NIS}-\mathrm{TtOH}, \mathrm{CH}_{2} \mathrm{Cl}_{2},-78^{\circ} \mathrm{C}$ to $0^{\circ} \mathrm{C}$ (for $\mathrm{SPh}$ ) \\
$\mathrm{SnCl}$ & $-\mathrm{AgB}\left(\mathrm{C}_{6} \mathrm{~F}_{5}\right)_{4}, \mathrm{BTF}, 25^{\circ} \mathrm{C}$ (for $\mathrm{F}$ )
\end{tabular}

$48 \alpha-S P h$

\begin{tabular}{|c|c|c|c|}
\hline Entry & Donor & $\mathrm{ROH}$ & $\begin{array}{l}\% \text { Yield of glycosylated } \\
\text { products (a/s ratio) }\end{array}$ \\
\hline 1 & 47 & 23 & 95 (only $\beta$ ) \\
\hline 2 & 48 & 23 & $95(2.5: 1)$ \\
\hline 3 & 47 & 24 & $84(1.2: 1)$ \\
\hline 4 & 48 & 24 & $99(4.0: 1)$ \\
\hline 5 & 47 & 25 & $87(2.2: 1)$ \\
\hline 6 & 48 & 25 & $94(3.0: 1)$ \\
\hline
\end{tabular}




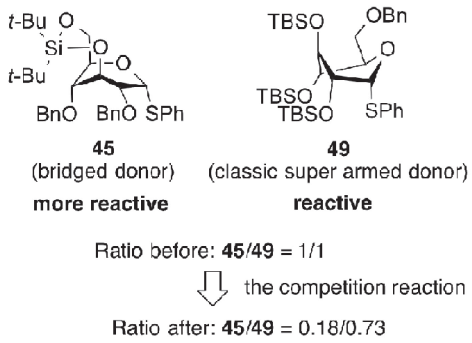

Fig.10: Ratio of donors before and after a competition reaction.

\section{5. $\alpha$-Glucosides}

Contrary to $\beta$-glucosylation with 3,6-DTBS-tethered fluoride donors, as discussed in section 2.4, glucosylation with 4,6-DTBStethered thioglycoside donors appears to be $\alpha$-selective. Recently, Heuckendorff and Jensen (2016) reported $\alpha$-glucosylations using 4,6- $O$-DTBS-tethered thioglycoside donors $\mathbf{5 0}$ and $\mathbf{5 1}$ in which the stereoselectivities are independent of promoter system, reaction temperature, leaving group, and anomeric configuration (Table 6). Moreover, it was demonstrated that triflate ions are not crucial for good $\alpha$-selectivity. Based on the experiments performed, it was suggested that the 4,6-O-tethering by the DTBS group (or the benzylidene group) induces $\alpha$-selectivity due to conformational restriction of oxocarbenium intermediates which favors $\alpha$-attack from the nucleophile. This interpretation is similar to that for the other DTBS-directed stereoselective glycosylations.

Table 6: Glycosylations of various acceptors with 4,6-DTBS-tethered Glc donors.

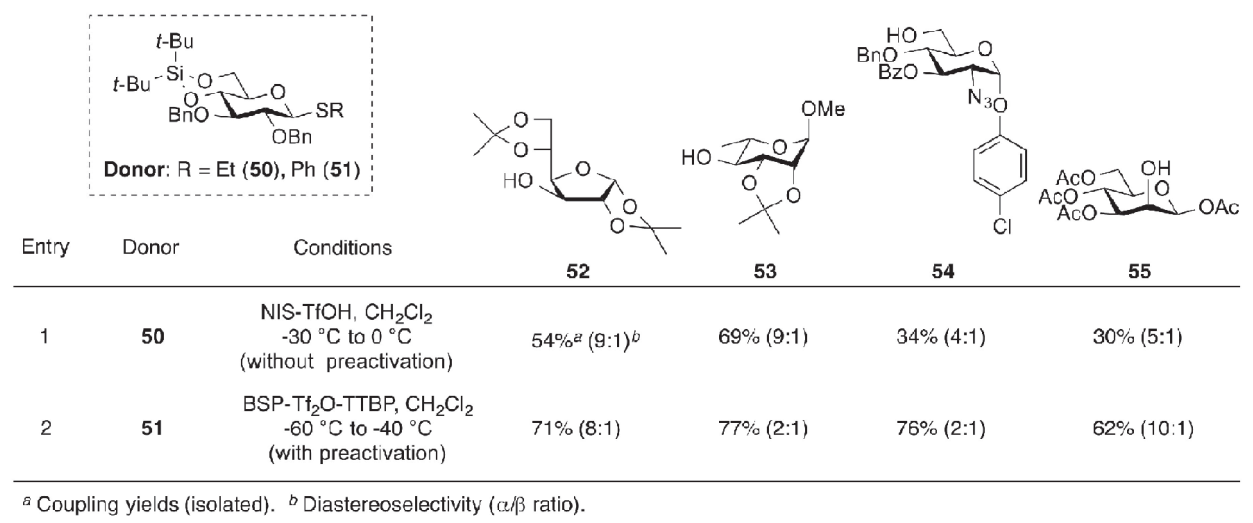

\section{6. $\beta$-Mannosides}

The synthesis of $\beta$-mannosides is one of the most difficult and challenging tasks in synthetic carbohydrate chemistry, whereas $\alpha$-mannosides are easily accessible with a 2-O-acylated donor through neighboring group participation (Paulsen, 1982; Ishiwata and Ito, 2008). The most direct and general method is the glycosylation reaction developed by Crich and Sun (1996, 1998 ) in which either 4,6-O-benzylidene-protected mannosyl thioglycoside $\mathbf{5 6}$ or a sulfoxide donor is utilized as a key derivative, and after preactivation of the donor at low temperature it can be converted in situ into the $\alpha$-triflate intermediate $\mathbf{5 7}$ that reacts with inversion to produce the $\beta$-mannosides $\mathbf{5 8}$ (Scheme 3). Recently, Heuckendorff et al., (2014) have reported $\beta$-selective mannosylation inspired by the Crich method. They prepared the 4,6-DTBS-tethered thiomannosyl donor $\mathbf{5 9}$ instead of the 4,6-benzylidene-tethered thiomannosyl donor $\mathbf{5 6}$ and examined the reactivity and stereoselectivity differences observed between silylene and benzylidene donors. Although $\beta$-selectivities are obtained under a variety of activation conditions at low temperature, it was found that the NIS/TfOH protocol is most suitable for making $\beta$-mannosides (Table 7). In entry 2 , starting and running the reaction at $25^{\circ} \mathrm{C}$ does not significantly change the yield and stereoselectivity. Intriguingly, even the activating system without the $\alpha$-triflate, i.e., the $\mathrm{AgClO}_{4} / t$ - $\mathrm{BuBr}$ system, affords good yield and $\beta$-selectivity $(86 \%, \beta / \alpha=5 / 1$, entry 4$)$. These results suggest that the $\alpha$-triflate as an intermediate is not essential for $\beta$-selectivity and may not be necessary in the formation of $\beta$-mannosides. Conversely, reaction of the perbenzylated donor $\mathbf{6 0}$ is not selective, confirming the importance of the 4,6-tethering group for $\beta$-selectivity (Entry 6). As illustrated in Fig. 11 , it was proposed that the $\beta$-selective mannosylation in the silylene case would involve the formation of the solventseparated oxocarbenium ion pairs $68 / 69$ and attack on 69 , the conformation of which $\left(B_{2,5}\right)$ is energetically favored over that of $68\left({ }^{4} \mathrm{H}_{3}\right)$ conformation, and is highly $\beta$-selective owing to the axial 
approach of the acceptor alcohol, resulting in a ${ }^{1} S_{5}$ conformation. This transfers into the low energy ${ }^{4} C_{1}$ via a ${ }^{4} H_{5}$ conformation, without significant staggering in the silylene ring. Conversely, $\alpha$-attack on 69 leads to a more strained and unfavorable ${ }^{\circ} S_{2}$ conformation and also would result in eclipsing interactions between the nucleophile and the almost axial 2-H (Fig. 11).

Scheme 3. Crich's method for $\beta$-mannoside synthesis.

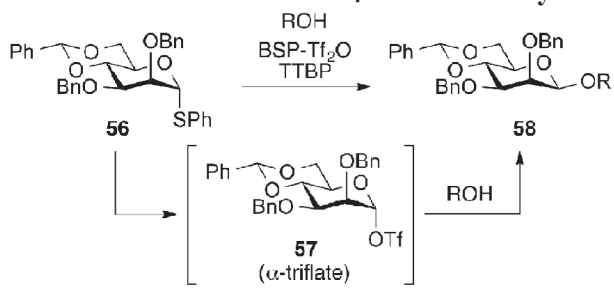

Table 7: Glycosylations with Man donors using NIS and various acid catalysts.
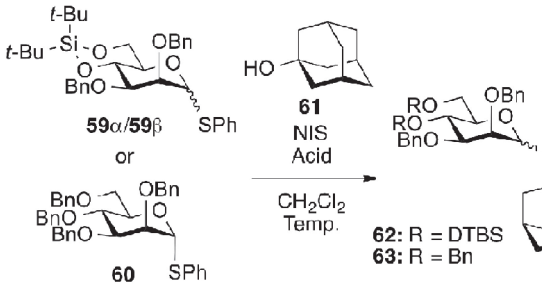

Temp.

\begin{tabular}{cccrcc} 
Entry & Donor & Acid & Temp $\left({ }^{\circ} \mathrm{C}\right)$ & Prod. & $\begin{array}{c}\% \\
\%\end{array}$ \\
\hline 1 & $59 \alpha$ & Tfold of prod ratio $)$ & -78 to 0 & 62 & $99(6: 1)$ \\
2 & $59 \alpha$ & TfOH & 25 & 62 & $80(4: 1)$ \\
3 & $59 \alpha$ & TMSOTf & -78 to 0 & 62 & $82(6: 1)$ \\
4 & $59 \alpha$ & $\mathrm{AgClO}_{4}{ }^{-2} \mathrm{BuBr}$ & 25 & 62 & $86(5: 1)$ \\
5 & $59 \beta$ & $\mathrm{TfOH}$ & -78 to 0 & 62 & $99(6: 1)$ \\
6 & 60 & $\mathrm{TfOH}$ & -78 to 0 & 63 & $87(1: 1)$
\end{tabular}

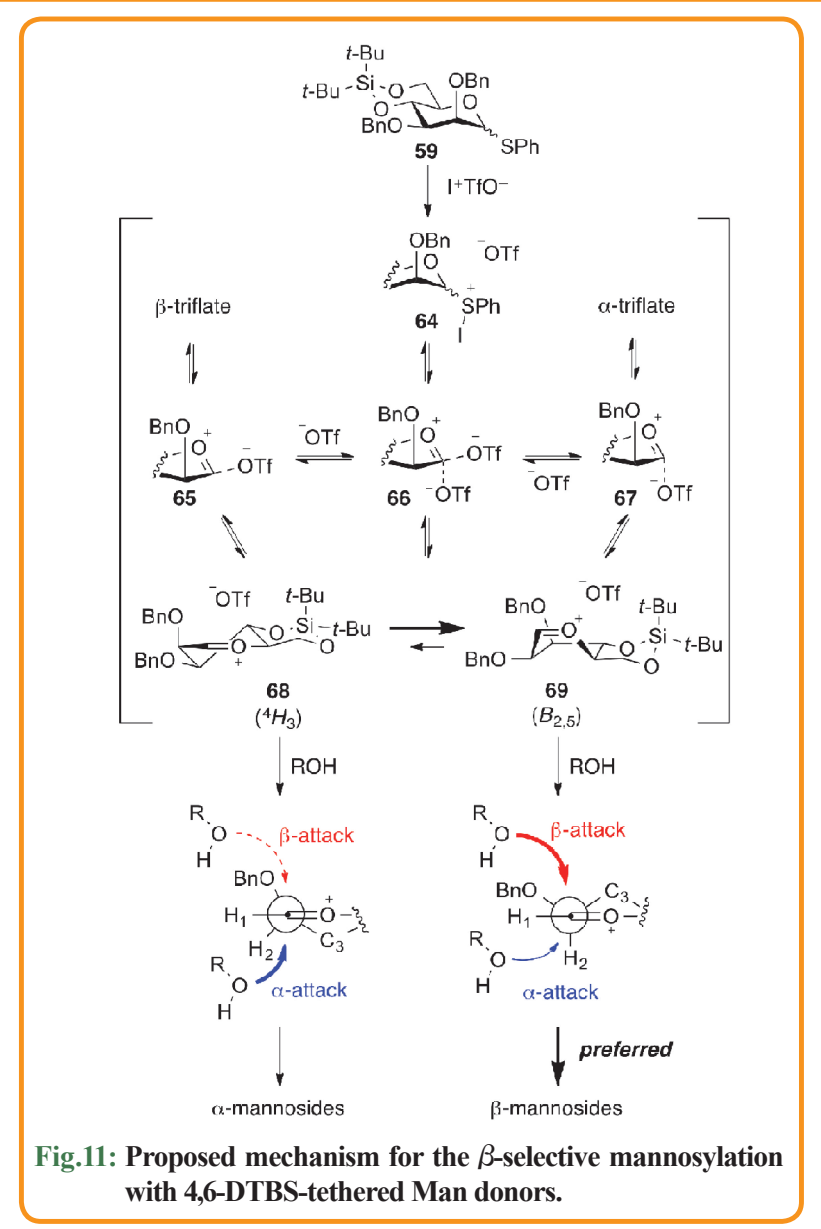

\section{7. $\beta$-Glucuronides}

The synthesis of $\beta$-glucuronides, which are mainly found as a constituent of glycosaminoglycans in nature, is usually performed using neighboring group participation by C2 acyl functionality. Furukawa et al., (2012) achieved the strict $\beta$-selective glucuronylation without the use of neighboring group participation for the first time. They designed 2,4-O-DTBSprotected glucuronate derivative $\mathbf{7 0}$ as a glycosyl donor because it must be in the ${ }^{1} C_{4}$ conformation and would be expected to exhibit increased reactivity due to cooperative conformational and anomeric effects (Fig. 12). In the glycosidations of $\mathbf{7 0}$ with several acceptors including well-known less reactive alcohols, mediated by either the $\mathrm{Ph}_{2} \mathrm{SO} / \mathrm{Tf}_{2} \mathrm{O}$ or NIS/TfOH system, high yields and complete $\beta$-selectivities are observed. Successful results were obtained by Crich and Dudkin, (2001) even in the glycosylation with the C4 hydroxyl group of glucosamine derivative 71, which is notorious for its poor nucleophilicity (Scheme 4). These results demonstrate the high reactivity of 2,4-DTBS-tethered donor 70 and its general versatility for the synthesis of $\beta$-glucuronides. 
Please cite this article as

Yagami and Imamura, Reviews in Agricultural Science, 6: 1-20, 2018

http://dx.doi.org/10.7831/ras.6.1

Two-dimensional nuclear Overhauser enhancement spectroscopy (NOESY) measurement and a macro model calculation indicate strong interactions between the endo-t-Bu group, the anomeric proton ( $\mathrm{H}-1)$, and $\mathrm{H}-5$, suggesting that the endo-t-Bu group is located close to $\mathrm{C} 1$ and $\mathrm{C} 5$ and shields the $\alpha$-direction to preferentially produce the $\beta$-product (Fig. 12).
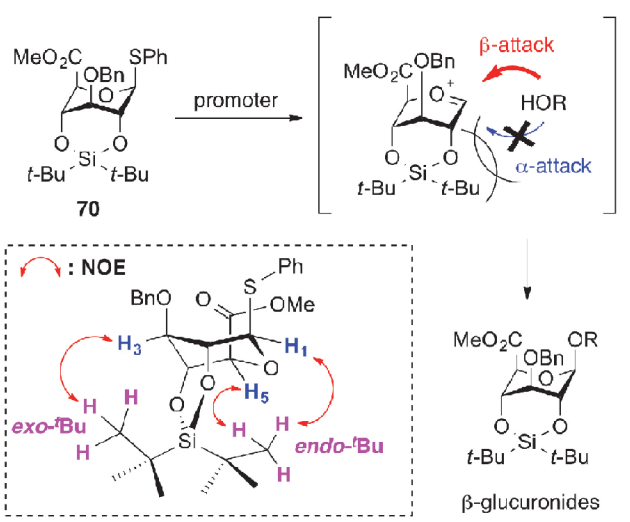

Structure of 70 based on the MM calculation

$$
\begin{aligned}
& \mathrm{MeO}_{2} \mathrm{C}_{\mathrm{OBn}} \mathrm{OR} \\
& \begin{array}{l}
O B n \\
\hline 07
\end{array} \\
& { }_{\mathrm{Bu}}^{\mathrm{O}} \mathrm{Si}^{-\mathrm{O}} \mathrm{-Bu}
\end{aligned}
$$

$\beta$-glucuronides

Fig.12: Working hypothesis for $\beta$-glucuronylation using the 2,4-DTBS-tethered GlcA donor.

Scheme 4. Strict $\beta$-selective glucuronylation of the hindered acceptor alcohol with less reactivity.

$$
\underbrace{\mathrm{Si}_{-\mathrm{O}}^{-\mathrm{O}-\mathrm{Bu}}}_{t-\mathrm{Bu}^{-}}
$$

70

Conditions:

(A) $\mathrm{Ph}_{2} \mathrm{SO}-\mathrm{Tf}_{2} \mathrm{O}-\mathrm{TTBP} / \mathrm{CH}_{2} \mathrm{Cl}_{2},-60^{\circ} \mathrm{C}$ to $0^{\circ} \mathrm{C}, 2 \mathrm{~h}, 63 \%$

(B) NIS-TiOH $/ \mathrm{CH}_{2} \mathrm{Cl}_{2},-40{ }^{\circ} \mathrm{C}$ to $-10{ }^{\circ} \mathrm{C}, 2 \mathrm{~h}, 70 \%$

\section{8. $\alpha$-Sialosides}

Stereocontrolled sialylation reactions have been performed through the use of nitrile solvents, pre-introduction of auxiliary groups loaded on either $\mathrm{C} 1$ carboxyl functionality or at the $\mathrm{C} 3$ position, and tuning of the $\mathrm{C} 5 \mathrm{~N}$-protecting groups. Hanashima et al. (2009a) reported that the use of silylene/oxazolidinone double-locked sialyl donors in the sialylation reaction affords $\alpha$ -sialosides predominantly, even in the non-participating solvent $\mathrm{CH}_{2} \mathrm{Cl}_{2}$. They found that an additional C-5,7-DTBS locking of the 5- $N, 4-O$-oxazolidinone bicyclic sialyl donor 73, which had been originally developed by Tanaka et al. (2006) as an $\alpha$ -directing sialyl donor, enabled preferential $\alpha$-stereoselectivity in sialylation. The double-locked sialyl donors $\mathbf{7 4}$ and $\mathbf{7 5}$ show comparable $\alpha$-selectivity with single-locked donor $\mathbf{7 3}$ when coupled with the 6-OH galactosyl acceptors 76-78 (Table 8). It was also found that the double-locked donors $\mathbf{7 4}$ and $\mathbf{7 5}$ give excellent $\alpha$-selectivity, even for the 3-OH galactosyl acceptors, whereas the use of single oxazolidinone-locked donor $\mathbf{7 3}$ diminishes $\alpha$-selectivity ( $\alpha / \beta=1: 2.5$ ) (Table 8 , entry 7). Conversely, when coupled with the relatively unreactive galactosyl acceptors $\mathbf{8 0}$ and $\mathbf{8 1}$ having the benzoyl group at the $\mathrm{C}-2$ position, the high $\alpha$-selectivity vanishes completely, even with double-locked donors. It was proposed that the silylene/oxazolidinone double-lock on $\mathbf{7 4}$ and $\mathbf{7 5}$ stabilizes the conformation of the pyranose ring more than in the single oxazolidinone-locked 73. Such conformational constraint would stabilize the plausible oxocarbenium intermediates 82/83. With regard to the coupling of reactive nucleophiles such as primary alcohols $\mathbf{7 6 - 7 8}$ and the 2-OBn-protected acceptor $\mathbf{7 9}$, the nucleophile would attack from the $\alpha$-face through an $\mathrm{S}_{\mathrm{N}} 2$-like pathway. In contrast, the less reactive 2-OBz-protected acceptors $\mathbf{8 0}$ and $\mathbf{8 1}$ would remain difficult to react with the relatively stable intermediate $\mathbf{8 2}$, which would decompose to give the highly reactive oxocarbenium ion $\mathbf{8 4}$, resulting in reaction with acceptors from the $\beta$-face to form $\beta$-sialosides (Scheme 5). 
Table 8: Sialylation reactions using double-locked sialyl donors $\mathbf{7 4 , 7 5}$, and oxazolidinone-type donor 73.

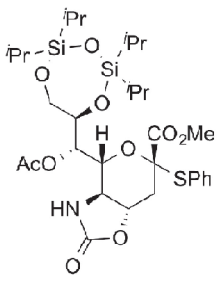

73

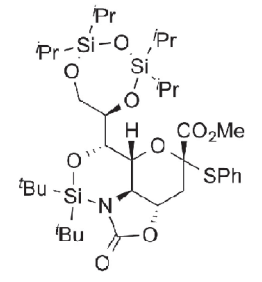

74

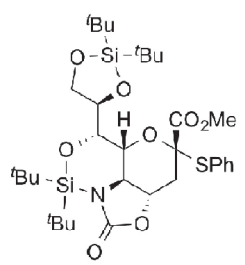

$$
\begin{aligned}
& \mathrm{ROH} \\
& \text { NIS } \\
& \begin{array}{l}
\mathrm{CH}_{2} \mathrm{Cl}_{2} \\
4 \AA \mathrm{MS}
\end{array} \\
& -40^{\circ} \mathrm{C}
\end{aligned}
$$

\begin{tabular}{|c|c|c|c|c|c|c|c|}
\hline Entry & Donor [equiv.] & $\mathrm{ROH}$ [equiv.] & $\begin{array}{l}\% \text { Yield of sialosides } \\
\qquad \alpha / \beta \text { ratio })\end{array}$ & Entry & Donor [equiv.] & $\mathrm{ROH}$ [equiv.] & $\begin{array}{c}\% \text { Yield of sialosides } \\
(\alpha / \beta \text { ratio })\end{array}$ \\
\hline 1 & $75[1.2]$ & ${ }_{76[1.0]}^{\mathrm{OB}}$ & $92 \%(\alpha / \beta=22: 1)$ & 5 & $75[1.2]$ & ${ }_{79[1.0]}^{\mathrm{OBn}_{\mathrm{OB}}^{\mathrm{OBn}}}$ & $83 \%$ (only $a$ ) \\
\hline 2 & $74[1.0]$ & $76[1.5]$ & $80 \%$ (only a) & 6 & $74[1.0]$ & $79[1.5]$ & $85 \%$ (only $\alpha$ ) \\
\hline 3 & $75[1.0]$ & Y7. & $88 \%$ (only $\alpha$ ) & 7 & $73[1.0]$ & ${ }_{80[1.0] \mathrm{OBz}} \mathrm{OMP}$ & $79 \%(\alpha / \beta=1: 2.5)$ \\
\hline 4 & $75[1.2]$ & $78[1.0]$ & $89 \%$ (only $a$ ) & 9 & $74[1.0]$ & $\underbrace{\mathrm{BzO}_{\mathrm{OMe}}}_{81[1.5]}$ & $86 \%$ (only $\beta$ ) \\
\hline
\end{tabular}$$
\text { TfOH }
$$

75

Scheme 5. Plausible reaction mechanism of sialylation using the double-locked donor 74.

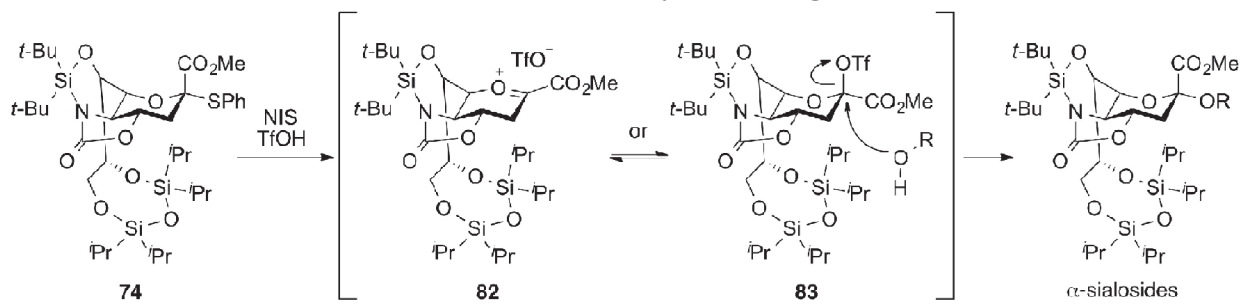

74

82

83
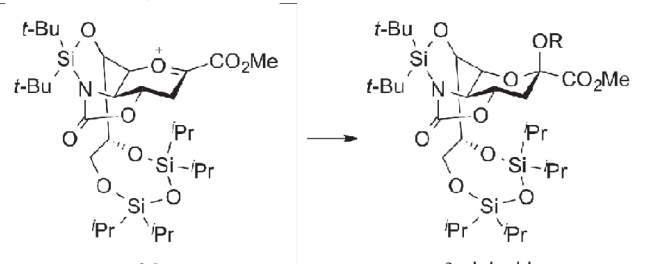

84

$\beta$-sialosides

Combination of $\alpha$-sialylation using DTBS/oxazolidinone double-lock sialyl donor $\mathbf{7 5}$ and $\alpha$-galactosylation with the 4,6-DTBS-protected galactosyl donor 85 (see section 2.1) enabled the efficient synthesis of the pentasaccharide moiety of starfish ganglioside AG2 (86), which possesses internal $\alpha$-Neu5Ac and $\alpha$-Gal units (Hanashima et al., 2009b) (Fig. 13). 


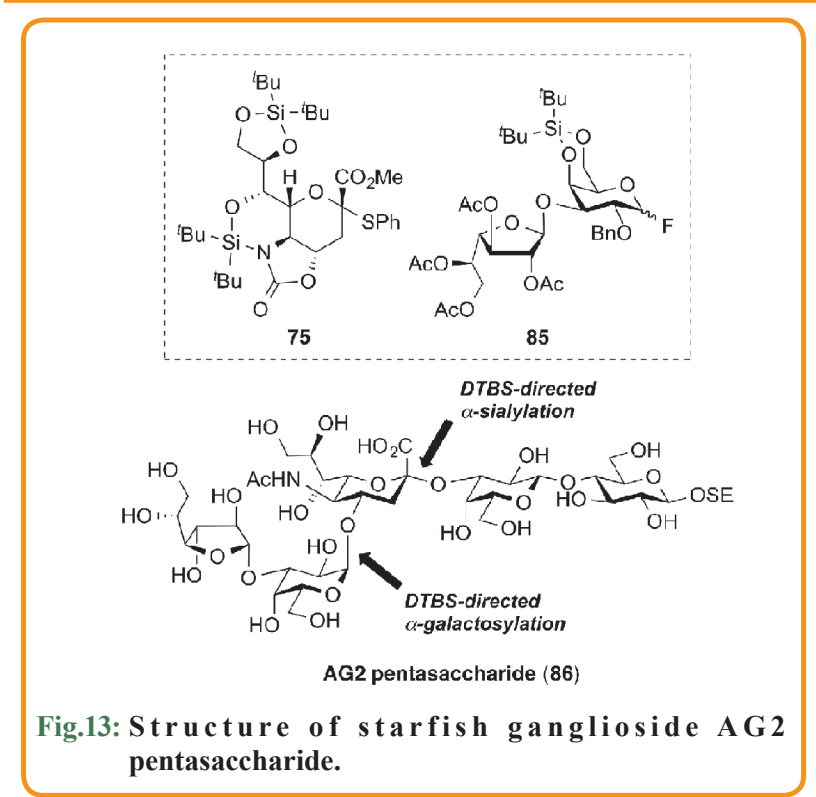

\section{9. $\alpha$-Kdo glycosides}

3-Deoxy-D-manno-oct-2-ulosonic acid (Kdo), a unique acidic eight-carbon sugar, is an essential structural constituent of polysaccharides found in bacteria. Although both $\alpha$ - and $\beta$-glycosides are found in nature, $\alpha$-glycosides are recognized as a fundamental component of the inner-core oligosaccharides of lipopolysaccharides. Chemical synthesis of $\alpha$-Kdo glycosides is potentially problematic due to the presence of the $\mathrm{C} 1$ electronwithdrawing carboxylic group to reduce the reactivity of the tertiary anomeric center and the C3-deoxy structure to form undesirable 2,3-glycal byproducts during the course of the glycosylation. Thus, an efficient and general Kdo glycosylation with high $\alpha$-stereoselectivity has still not been fully achieved. Recently, Huang et al. (2015) reported a strict stereoselective glycosylation method for $\alpha$-Kdo glycosides using 5,7-O-DTBSprotected ethylthioglycoside donors 89-91. They examined glycosylations of the glucose 6-OH acceptor 93 with 5,7-DTBStethered donors 89-91, which differ in terms of only the protecting group at the C8 position, as well as the analogous donors 87 and $\mathbf{8 8}$ tethered by isopropylidene or benzylidene group instead of the DTBS group. The donor protected as the 5,7-O-acetonide 87 displays no stereoselectivity but excellent yield, whereas the analogous 5,7-O-benzylidene-protected donor $\mathbf{8 8}$ gives the corresponding disaccharide in good yield with a high degree of $\alpha$-selectivity. However, the thioglycoside donors 89-91 bearing the 5,7-O-DTBS group exhibit complete $\alpha$-selectivity, and no $\beta$-stereoisomers were found even after column chromatographic purification. In contrast, the reaction of the 4,5,7-tri- $O$-Bz-8- $O$ TBS-protected donor $\mathbf{9 2}$ shows a reverse $\beta$-selectivity $(\alpha / \beta=1: 2.5)$
(Table 9). These results clearly indicate that tethering by the DTBS group at $\mathrm{C} 5$ and $\mathrm{C} 7$ positions enhances the $\alpha$-stereodirecting effect in the glycosidation of Kdo donors. Furthermore, it was found that tris(4-bromophenyl)ammoniumyl hexachloroantimonate (TBPA) is most effective for activating 5,7-DTBS-tethered Kdo thioglycoside donors including 89, especially in the coupling with the sterically hindered acceptors such as $\mathbf{9 3}$, resulting in the first direct assembly of a synthetically difficult $\alpha-(2,5) \mathrm{Kdo}-\mathrm{Kdo}$ linkages (Scheme 6). Finally, the 5,7-DTBS-tethered Kdo donors were successfully applied to the synthesis of biologically relevant $\alpha$-Kdo-containing oligosaccharides including the 4,8-branched trisaccharide 95 and the linear Kdo- $\alpha$ - $(2,8)-\mathrm{Kdo}-\alpha-(2,4)-\mathrm{Kdo}$ trisaccharide 96 (Fig. 14).

\section{Table 9: Effect of cyclic 5,7-O-acetals on glycosylation} stereoselectivity.

(8)



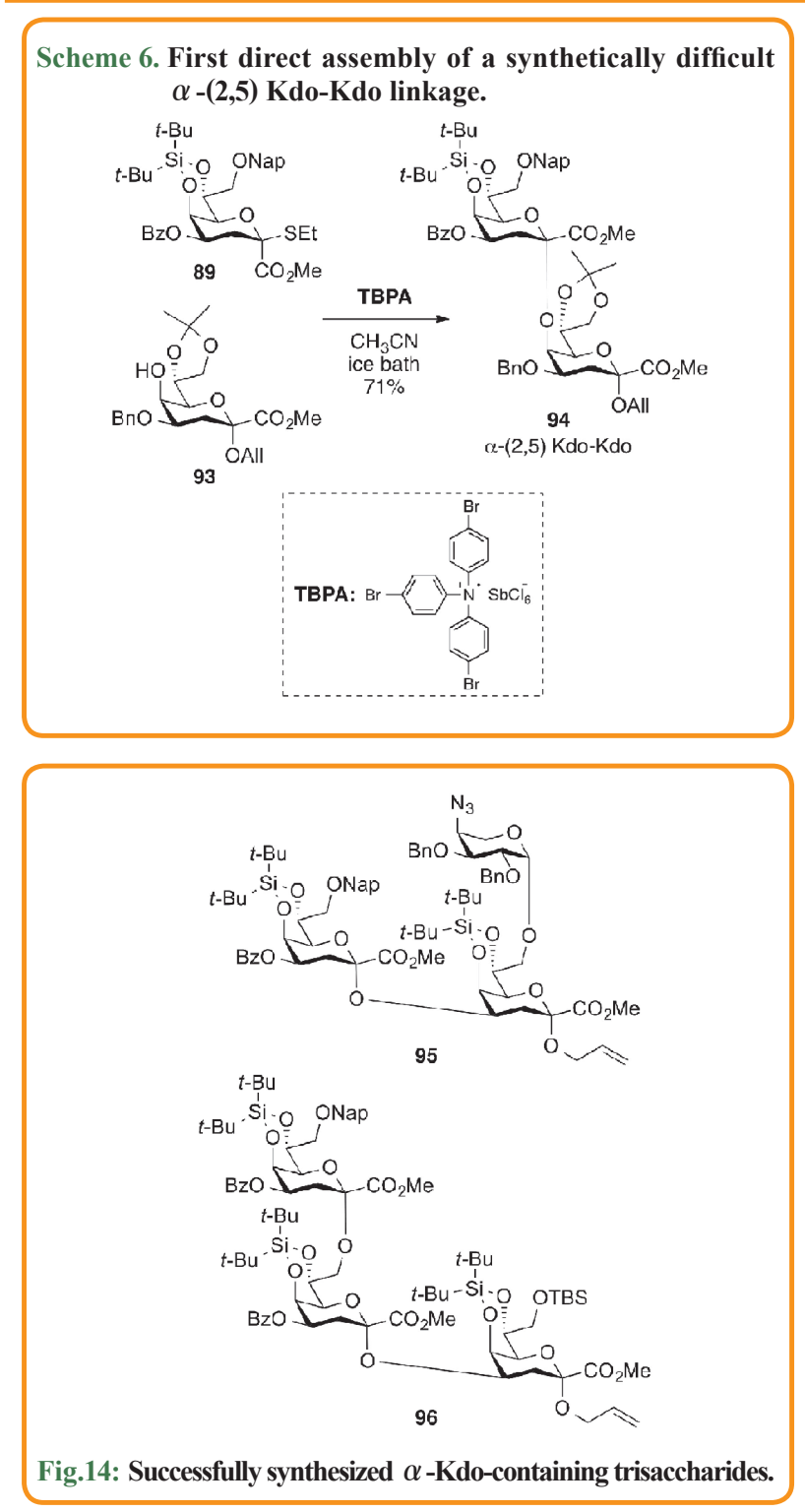

\section{TIPDS-directed stereoselective glycosylation}

\section{1. $\beta$-Arabinofuranosides}

In section 2.2, the $\beta$-stereoselective arabinofuranosylations using the 3,5-O-DTBS-protected donors developed by Rao and Boons (2007) as well as Crich et al. (2007) were described. As well as investigating Araf donors having a 3,5-DTBS-tethering, Ishiwata et al. (2006) have explored the possibility of achieving $\beta$-selective arabinofuranosylation by using 3,5-TIPDS-protected Araf donors 99 and $\mathbf{1 0 0}$. Investigation of the stereoselectivity using the 2,3-O-TIPDS-tethered analog 97, for which some $\beta$-selectivity was observed, revealed that 3,5 -tethering is most effective for enhancing $\beta$-selectivity (Table 10 ). Conversely, the non-cyclically protected donor 98 exhibits no $\beta$-selectivity. Importantly, the 3,5 -TIPDS protection imparts higher $\beta$-selectivity compared to that achieved with regioisomeric 3,5-DTBS protection. An explanation of the different selectivities between cyclic silyl protecting groups was suggested by Smith et al. (2003), in which the allylation of bicyclic lactol acetates $\mathbf{1 0 3}$ and $\mathbf{1 0 4}$ was investigated (Fig. 15). The eight-five bicyclic acetate $\mathbf{1 0 3}$ (as TIPDS simulant) gives higher $\beta$ -selectivity than the six-five counterpart 104 (as DTBS simulant). For both 107 and 108, the $\alpha$-attack of acceptor alcohols on the respective oxocarbenium intermediates $\mathbf{1 0 9}$ and $\mathbf{1 1 0}$ is disfavored due to the 1,2-gauche interactions between the entering acceptor and the pseudoaxially oriented C2 hydrogen atom. However, the $\beta$-attack in six-five bicyclic $\mathbf{1 1 0}$ should lead to an initial conformer with the 3,5-DTBS group possessing a distorted nonchair-like conformation, thereby reducing the preference of the pathway toward the $\beta$-isomer. Furthermore, molecular modeling studies of glycosylated products have shown that the total energy of the $\beta$-product is lower than that of the corresponding $\alpha$-isomer, suggesting that the formation of the $\beta$-isomer is the thermodynamically favored process. In the global minimum structure, the $\beta$-product has pseudoaxially oriented glycoside linkages, which might be favorable in light of the anomeric effect. 
Table 10: Coupling yields and the stereochemical outcome in glycosylations using Araf donors with different protection patterns.

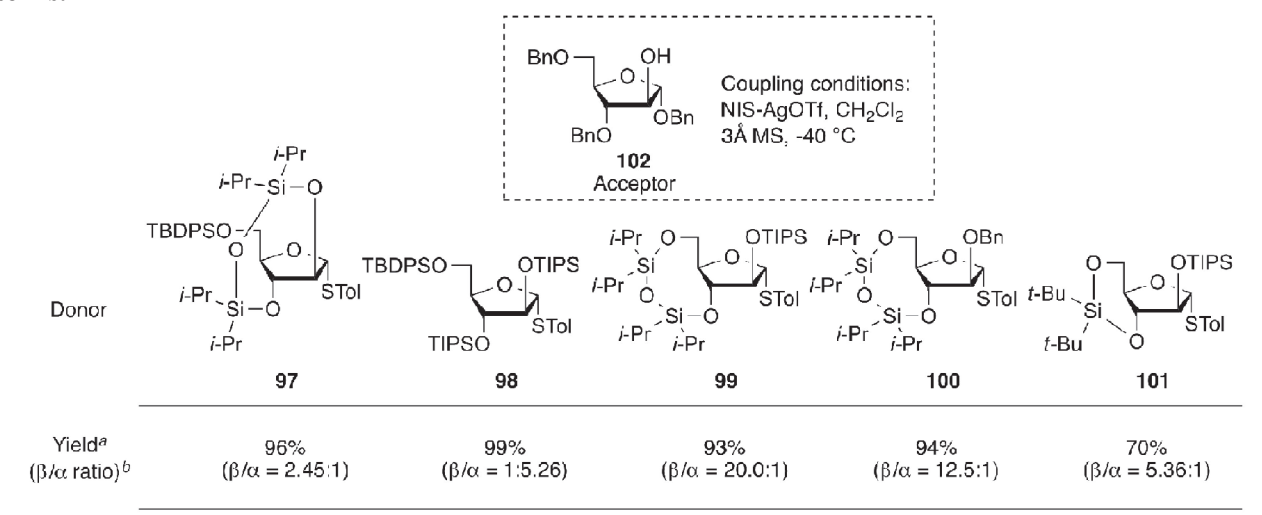

a Yield of the mixture of the isomers after gel filtration column chromatography.

$b$ Diastereomeric ratios determined by ${ }^{1} \mathrm{H}$ NMR.

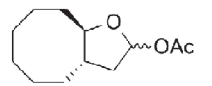

103<smiles>CC(=O)O[C@H]1C[C@H]2CCCC[C@@H]2O1</smiles>

104

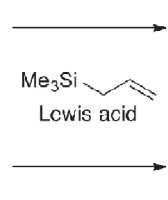

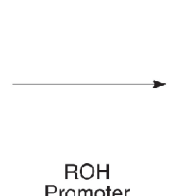

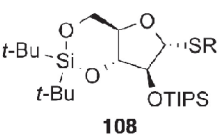

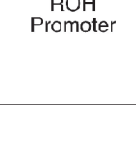

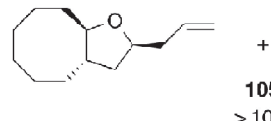

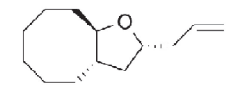

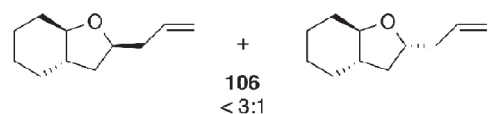
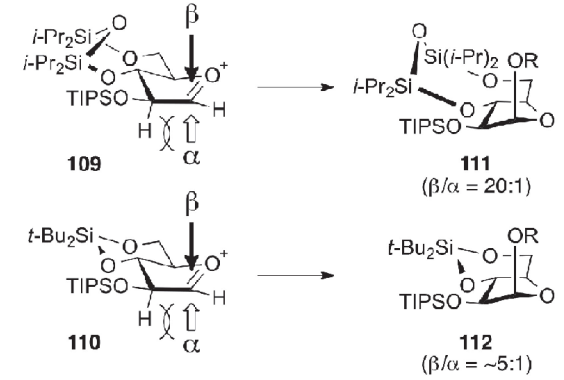

Fig.15: Plausible explanation for the $\beta$-selective addition to the activated donor.

In addition, it was found that the structure of acceptor alcohols strongly affects the stereoselectivity. To achieve high $\beta$-selective glycosylation, relatively bulky acceptor such as $\mathbf{1 0 2}$ should be used. A less hindered acceptor with a primary hydroxyl group exhibits no selectivity, suggesting that the steric factor plays a major role in controlling the stereochemical outcome in the glycosyaltion. It was speculated that, when the acceptor is not sufficiently hindered, steric repulsion with the $\mathrm{C} 2$ hydrogen is inconsequential.

The established $\beta$-selective arabinofuranosylation in the direct fashion was successfully applied to the assembly of $\beta$-Arafcontaining oligosaccharides including the docosasaccharide arabinan motif present in mycobacterial cell walls (Ishiwata and Ito, 2011).
Furthermore, it is noteworthy that very recently this methodology was adopted in the synthesis of the 92-mer polysaccharide $\mathbf{1 1 3}$ in mycobacterial arabinogalactan, the structure of which contains eight $\beta$-D-Araf linkages that are constructed with the 3,5-O-TIPDS-protected Araf donor 100 (Wu et al., 2017) (Fig. 16). 


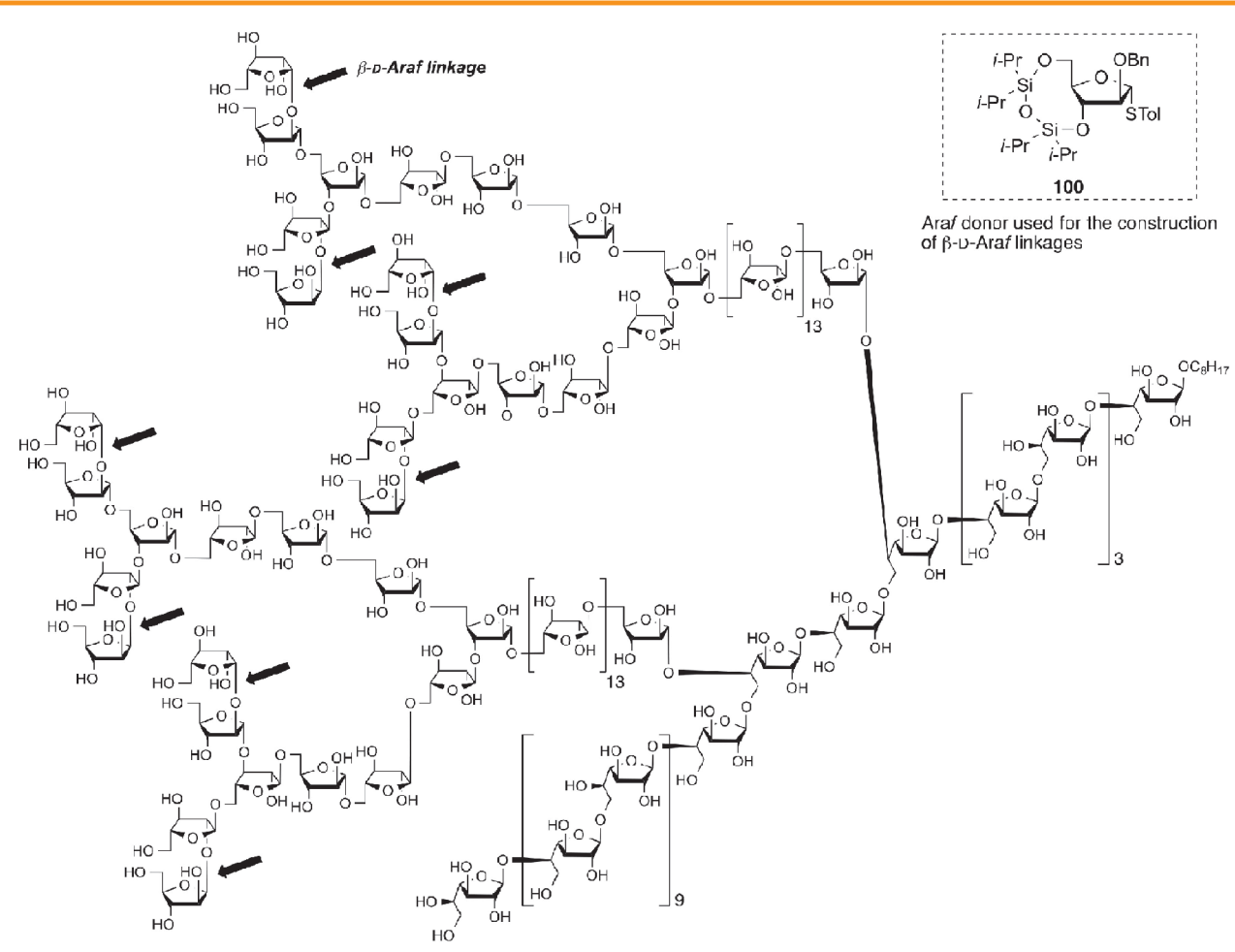

113

Fig.16: Successfully synthesized mycobacterial arabinogalactan containing 92 monosaccharide units with eight $\beta$-D-Araf residues.

\section{2. $\beta$-Glucosides}

As mentioned in section 2.4, 3,5-O-DTBS-tethered glucosyl donors exhibit $\beta$-stereoselectivity in glycosylation. Recently, our group (Yagami et al., 2017) have developed a $\beta$-selective glucosylation using 2,3-O-TIPDS-protected glucosyl donors. The tethering by the TIPDS group at the $\mathrm{C} 2$ and $\mathrm{C} 3$ positions loosely restricts the ring conformation of the glucose donor in both the ground state and the corresponding oxocarbenium intermediate. The glycosylation of glycosyl acceptor 77 with the loosely ring-restricted donor 114, promoted by the NIS/TfOH system in $\mathrm{CH}_{2} \mathrm{Cl}_{2}$ at $-80{ }^{\circ} \mathrm{C}$, affords the corresponding disaccharide $\mathbf{1 1 5}$ in excellent yield with a high degree of $\beta$-selectivity $(97 \%, \alpha / \beta=1: 10.1)$ (Scheme 7). Attempts to prepare the 2,3-O-DTBS-protected analog in this study failed due to its lability, presumably owing to its conformationally rigidity. Although the precise mechanism for such $\beta$-selectivity has not yet been elucidated, it is unlikely that the increased $\beta$-selectivity can be ascribed to the simple steric effect of the bulky TIPDS group.

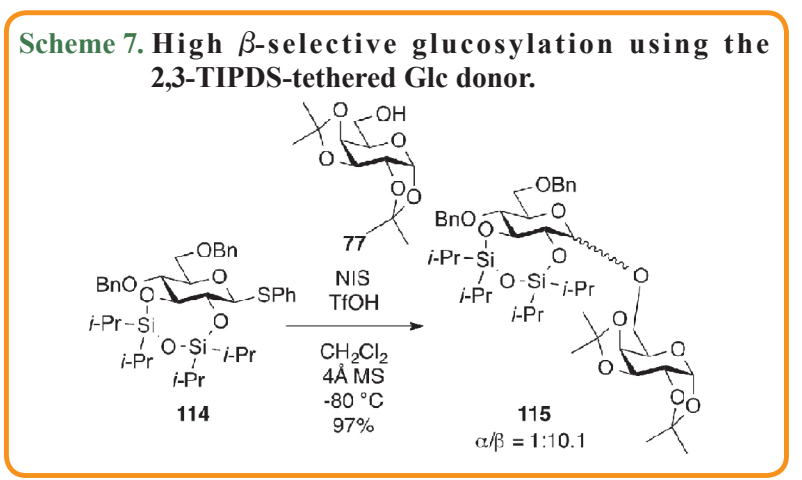

3.3. Mechanistic study on the stereoselectivity of glycosylation with TIPDS-protected furanosyl donors

Lavinda et al. (2014) have reported mechanistic studies on the stereoselectivity in glycosylation with a cyclic silylprotected furanosyl donor. Their work indicated that nucleophilic attack on a furanosyl oxocarbenium ion would favor the "inside attack" in the envelope conformation. In case of $\beta$-selective L-arabinofuranosylation by Zhu et al. (2006) (presented in section 2.2), it is thought that the DTBS-locked arabinofuranosyl donor fixed in the $E_{3}$ conformation in which nucleophilic attack from the 
Please cite this article as

Yagami and Imamura, Reviews in Agricultural Science, 6: 1-20, 2018

http://dx.doi.org/10.7831/ras.6.1

$\beta$-face "inside attack" is favored, resulting in high $\beta$-selectivity. In addition, Tran and Woerpel (2013) published a study on the origin of high stereoselectivity in cyclic silyl-protected bicyclic glycosyl donors; their experiments involved the syntheses of a series of bicyclic glycosyl donors containing a disiloxane ring. It is significant that Tran and Woerpel (2013) investigated the selectivity, by not only computational methods like molecular modeling but also by experimental methods employing judiciously designed synthetic derivatives. They investigated the $C$-allylation of the bicyclic lactol acetate of 2-deoxyribose as a model experiment (Fig. 17). First, Tran and Woerpel (2013) focused on the opposite stereoselectivity between the eight-five bicyclic donor with constraint imposed by the cyclooctane ring to give 1,3-trans selectivity (93:7) and the eight-five bicyclic donor with 3,5-O-TIPDS protecting group to give 1,3-cis selectivity (84:16). To evaluate the differences, nine-five bicyclic donors with the TIPDS group (118 and 119) were synthesized and subjected to $C$-allylation under the same conditions. As a result, the donor 118, which possesses an electronegative oxygen atom at $\mathrm{C} 3$, was found to provide the same 1,3-cis product as $\mathbf{1 1 7}$, while the donor 119 without oxygen at C3 gives the opposite 1,3-trans product predominantly. The stereoselectivity in the nine-five ring 118 (>95:5) is better than that in the eight-five ring 117 (84:16). Meanwhile, the lowest energy conformer of the oxocarbenium ions of $\mathbf{1 1 7}$ and $\mathbf{1 1 8}$ were investigated by computational analysis. It was found that the relative energy gap between the lowest energy 3,4-diequatorial conformer and 3,4-diaxial conformer for the oxocarbenium ion generated from $\mathbf{1 1 7}$ is very small, while the 3,4-diaxial conformer in $\mathbf{1 1 8}$ is energetically more stable than the diequatorial one. Concurrently, the oxocarbenium ion derived from 118 probably presents mainly in the diaxial conformation and that of $\mathbf{1 1 7}$ may not be in any particular conformation. This suggests that the less flexible oxocarbenium ion conformer would allow nucleophilic attack by nucleophiles from a certain direction, leading to enhancement of the stereoselectivity. In accordance with the presented data, the stereoselectivity in the cyclic silylprotected furanosyl donor system can be rationalized as follows: 1) The stereoselectivity depends on possibility of "inside attack" by nucleophiles. 2) The high frequency of the energetically stable conformer of oxocarbenium ion enhances the stereoselectivity. 3) The conformation of the oxocarbenium ion is governed by stereoelectronic effects resulting from the presence of an electronegative oxygen atom at $\mathrm{C} 3$, affecting the stereoselectivity.

Nevertheless, the present finding for the $C$-allylation of 2-deoxyD-ribose is not consistent with the result using D-arabinofuranose, as reported by Ishiwata et al. (2006) (preferable formation of 1,3-trans$O$-glycoside). The difference of stereoselectivity between 2-deoxyD-ribose and D-arabinofuranose may be attributed to the presence or absence of a hydroxyl group (as well as substituents on it) at the $\mathrm{C} 2$ position that changes the conformational preference of the oxocarbenium ions.

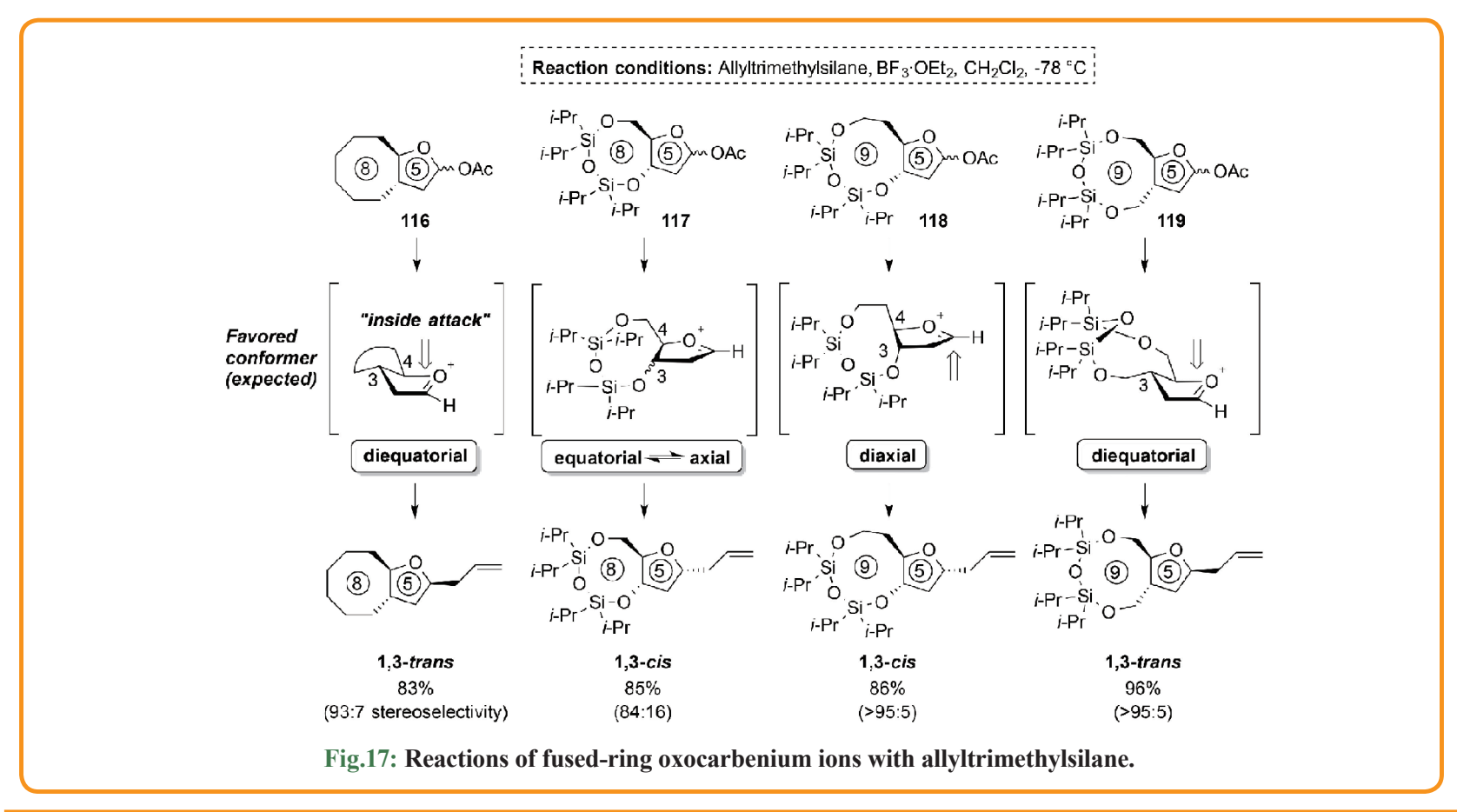




\section{Conclusion}

It has been demonstrated that glycosylations using DTBSand TIPDS-protected glycosyl donors of diverse sugar residues can deliver the corresponding glycosylated products with high stereoselectivity. In particular, DTBS protection can impart prominent stereoselectivity in the construction of $\alpha$-Gal/GalNAc, $\beta$-GlcA, and $\alpha$-Kdo linkages, in which the high stereoselectivities are independent of the reaction conditions. Even though the detailed mechanism for high stereoselectivity is not yet fully understood and requires further study, the conformational preference of the oxocarbenium ion intermediates governed by the ring-restriction and stereoelectronic effects resulting from the presence of electronegative oxygen atoms plays a significant role in the stereoselectivity. In addition, the steric hindrance induced by bulky substituents such as $t$-butyl and $i$-propyl groups is of great importance for deciding the direction of nucleophile attack, affecting the stereochemical outcome in the glycosylation.

Finally, the potential of cyclic protection by silyl protecting groups for stereoselective glycosylations has been generally recognized in the field of carbohydrate chemistry in the past 15 years and has undoubtedly facilitated the assembly of structurally complex carbohydrate molecules. Thus, further studies on this field will be of benefit to the development of glycobiology as well as glycochemistry.

\section{Acknowledgement \\ A segment of the study described here was supported by JSPS KAKENHI Grant Number JP16K18694.}

\section{REFERENCES}

Boltje TJ, Zhong W, Park J, Wolfert MA, Chen W and Boons GJ (2012) Chemical synthesis and immunological evaluation of the inner core oligosaccharide of Francisella tularensis. J. Am. Chem. Soc., 134: 14255-14262.

Crich D and Dudkin V (2001) Why are the hydroxy groups of partially protected $\mathrm{N}$-acetylglucosamine derivatives such poor glycosyl acceptors, and what can be done about it? A comparative study of the reactivity of $\mathrm{N}$-acetyl-, $\mathrm{N}$-phthalimido-, and 2-azido2-deoxy-glucosamine derivatives in glycosylation. 2-Picolinyl ethers as reactivity-enhancing replacements for benzyl ethers. J. Am. Chem. Soc., 123: 6819-6825.

Crich D, Pedersen CM, Bowers AA and Wink DJ (2007) On the use of 3,5-O-benzylidene and 3,5-O-(di-tert-butylsilylene)-2-Obenzylarabinothiofuranosides and their sulfoxides as glycosyl donors for the synthesis of $\beta$-arabinofuranosides: Importance of the activation method. J. Org. Chem., 72: 1553-1565.

Crich D and Sun S (1996) Formation of $\beta$-mannopyranosides of primary alcohols using the sulfoxide method. J. Org. Chem., 61:
4506-4507.

Crich D and Sun S (1998) Direct chemical synthesis of $\beta$-mannopyranosides and other glycosides via glycosyl triflates. Tetrahedron, 54: 8321-8348.

Furukawa T, Hinou H and Nishimura S (2012) Strict stereocontrol by 2,4 - $O$-di-tert-butylsilylene group on $\beta$-glucuronylations. Org. Lett., 14: 2102-2105.

Gadikota RR, Callam CS and Lowary TL (2001) Stereocontrolled synthesis of 2,3-anhydro- $\beta$-D-lyxofuranosyl glycosides. Org. Lett., 3: 607-610.

Gadikota RR, Callam CS, Wagner T, Fraino BD and Lowary TL (2003) 2,3-Anhydro sugars in glycoside bond synthesis. Highly stereoselective syntheses of oligosaccharides containing $\alpha$ - and $\beta$-arabinofuranosyl linkages. J. Am. Chem. Soc., 125: 41554165.

Goto K, Sawa M, Tamai H, Imamura A, Ando H, Ishida H and Kiso M (2016) The total synthesis of starfish ganglioside GP3 bearing a unique sialyl glycan architecture. Chem. Eur. J., 22: 8323-8331.

Goto K, Suzuki T, Tamai H, Ogawa J, Imamura A, Ando H, Ishida $\mathrm{H}$ and Kiso $\mathrm{M}$ (2015) Total synthesis and neuritogenic activity evaluation of ganglioside PNG-2A from the starfish Protoreaster nodosus. Asian J. Org. Chem., 4: 1160-1171.

Hagen B, van Dijk JHM, Zhang Q, Overkleeft HS, van der Marel GA and Codée JDC (2017) Synthesis of the Staphylococcus aureus Strain M capsular polysaccharide repeating unit. Org. Lett., 19: 2514-2517.

Hanashima S, Sato K, Ito Y and Yamaguchi Y (2009a) Silylene/ oxazolidinone double-locked sialic acid building blocks for efficient sialylation reactions in dichloromethane. Eur. J. Org. Chem., 4215-4220.

Hanashima S, Yamaguchi Y, Ito Y and Sato K (2009b) Synthesis of the starfish ganglioside AG2 pentasaccharide. Tetrahedron Lett., 50: 6150-6153.

Hara A, Imamura A, Ando H, Ishida H and Kiso M (2014) A new chemical approach to human ABO histo-blood group type 2 antigens. Molecules, 19: 414-437.

Heuckendorff M, Bendix J, Pedersen CM and Bols M (2014) $\beta$-Selective mannosylation with a 4,6-silylene-tethered thiomannosyl donor. Org. Lett., 16: 1116-1119.

Heuckendorff M and Jensen HH (2016) On the gluco/manno paradox: Practical $\alpha$-glucosylations by NIS/TfOH activation of 4,6-O-tethered thioglucoside donors. Eur. J. Org. Chem., 51365145.

Heuckendorff M, Pedersen CM and Bols M (2013) Conformationally armed 3,6-tethered glycosyl donors: Synthesis, conformation, reactivity, and selectivity. J. Org. Chem., 78: 7234-7248. 
Please cite this article as

Yagami and Imamura, Reviews in Agricultural Science, 6: 1-20, 2018

http://dx.doi.org/10.7831/ras.6.1

Huang JS, Huang W, Meng X, Wang X, Gao PC and Yang JS (2015) Stereoselective synthesis of $\alpha$-3-deoxy-D-manno-oct-2-ulosonic acid ( $\alpha$-Kdo) glycosides using 5,7-O-di-tert-butylsilyleneprotected Kdo ethyl thioglycoside donors. Angew. Chem. Int. Ed., 54: 10894-10898.

Imamura A, Ando H, Ishida $\mathrm{H}$ and Kiso M (2005) Ditert-butylsilylene-directed $\alpha$-selective synthesis of 4-methylumbelliferyl T-antigen. Org. Lett., 7: 4415-4418.

Imamura A, Ando H, Ishida H and Kiso M (2008a) DTBS(di-tertbutylsilylene)-directed $\alpha$-galactosylation for the synthesis of biologically relevant glycans. Curr. Org. Chem., 12: 675-689.

Imamura A, Ando H, Ishida H and Kiso M (2008b) DTBS effect: The unique sterically driven director for $\alpha$-galactosylation. Heterocycles, 76: 883-908.

Imamura A, Ando H, Korogi S, Tanabe G, Muraoka O, Ishida $\mathrm{H}$ and Kiso M (2003) Di-tert-butylsilylene (DTBS) groupprotected $\alpha$-selective galactosylation unaffected by $\mathrm{C}-2$ participating functionalities. Tetrahedron. Lett., 44: 6725-6728.

Imamura A, Kimura A, Ando H, Ishida H and Kiso M (2006) Extended applications of di-tert-butylsilylene-directed $\alpha$-predominant galactosylation compatible with C2-participating groups toward the assembly of various glycosides. Chem. Eur. J., 12: 8862-8870.

Imamura A, Matsuzawa N, Sakai S, Udagawa T, Nakashima $\mathrm{S}$, Ando H, Ishida $\mathrm{H}$ and Kiso $\mathrm{M}$ (2016) The origin of high stereoselectivity in di-tert-butylsilylene-directed $\alpha$-galactosylation. J. Org. Chem., 81: 9086-9104.

Ishiwata A, Akao H and Ito Y (2006) Stereoselective synthesis of a fragment of mycobacterial arabinan. Org. Lett., 8: 5525-5528.

Ishiwata A and Ito Y (2008) Stereoselective synthesis of $\beta$-mannoglycosides. In: Glycoscience - Chemistry and Chemical Biology (Fraser-Reid B, Tatsuta K, Thiem J. eds.). pp. 12791312. Springer-Verlag Berlin Heidelberg. New York

Ishiwata A and Ito Y (2011) Synthesis of docosasaccharide arabinan motif of mycobacterial cell wall. J. Am. Chem. Soc., 133: 2275-2291.

Joe M, Bai Y, Nacario RC and Lowary TL (2007) Synthesis of the docosanasaccharide arabinan domain of mycobacterial arabinogalactan and a proposed octadecasaccharide biosynthetic precursor. J. Am. Chem. Soc., 129: 9885-9901.

Kimura A, Imamura A, Ando H, Ishida H and Kiso M (2006) A novel synthetic route to $\alpha$-galactosyl ceramides and iGb3 using DTBS-directed $\alpha$-selective galactosylation. Synlett, 15: 23792382

Komori T, Ando T, Imamura A, Li YT, Ishida H and Kiso M (2008) Design and efficient synthesis of novel GM2 analogues with respect to the elucidation of the function of GM2 activator. Glycoconj. J., 25: 647-661.
Lavinda O, Tran VT and Woerpel KA (2014) Effect of conformational rigidity on the stereoselectivity of nucleophilic additions to five-membered ring bicyclic oxocarbenium ion intermediates. Org. Biomol. Chem., 12: 7083-7091.

Lee A, Farrand KJ, Dickgreber N, Hayman CM, Jürs S, Hermans IF and Painter GF (2006) Novel synthesis of $\alpha$-galactosylceramides and confirmation of their powerful NKT cell agonist activity. Carbohydr. Res., 341: 2785-2798.

Miljkovic M, Yeagley D, Deslongchamps P and Dory YL (1997) Experimental and theoretical evidence of throughspace electrostatic stabilization of the incipient oxocarbenium ion by an axially oriented electronegative substituent during glycopyranoside acetolysis. J. Org. Chem., 62: 7597-7604.

Okada Y, Asakura N, Bando M, Ashikaga Y and Yamada H (2012) Completely $\beta$-selective glycosylation using 3,6- $O$-(o-xylylene)bridged axial-rich glucosyl fluoride. J. Am. Chem. Soc., 134: 6940-6943.

Paulsen H (1982) Advances in selective chemical syntheses of complex oligosaccharides. Angew. Chem. Int. Ed., 21: 155-173.

Rao Y and Boons GJ (2007) A highly convergent chemical synthesis of conformational epitopes of rhamnogalacturonan II. Angew. Chem. Int. Ed., 46: 6148-6151.

Sato T, Imamura A, Ando H, Ishida H and Kiso M (2009) Di-tertbutylsilylene-directed $\alpha$-selective synthesis of $p$-nitrophenyl T-antigen analogues. Glycoconj. J., 26: 83-98.

Smith DM, Tran MB and Woerpel KA (2003) Nucleophilic additions to fused bicyclic five-membered ring oxocarbenium ions: Evidence for preferential attack on the inside face. J. Am. Chem. Soc., 125: 14149-14152.

Tanaka H, Nishiura Y and Takahashi T (2006) Stereoselective synthesis of oligo- $\alpha-(2,8)$-sialic acids. J. Am. Chem. Soc., 128: 7124-7125.

Tilve MJ and Gallo-Rodriguez C (2011) Glycosylation studies on conformationally restricted 3,5-O-(di-tert-butylsilylene)D-galactofuranosyl trichloroacetimidate donors for 1,2-cis $\alpha$-D-galactofuranosylation. Carbohydr. Res., 346: 2838-2848.

Tilve MJ and Gallo-Rodriguez C (2014) Conformationally restricted 3,5-O-(di-tert-butylsilylene)-D-galactofuranosyl thioglycoside donor for 1,2-cis $\alpha$-D-galactofuranosylation. Carbohydr. Res., 397: 7-17.

Tran VT and Woerpel KA (2013) Nucleophilic addition to silylprotected five-membered ring oxocarbenium ions governed by stereoelectronic effects. J. Org. Chem., 78: 6609-6621.

Wang Y, Maguire-Boyle S, Dere RT and Zhu X (2008) Synthesis of $\beta$-D-arabinofuranosides: stereochemical differentiation between D- and L-enantiomers. Carbohydr. Res., 343: 31003106.

Wu Y, Xiong DC, Chen SC, Wang YS and Ye XS (2017) Total 
synthesis of mycobacterial arabinogalactan containing 92 monosaccharide units. Nat. Commun., 8: 14851.

Yagami N, Tamai H, Udagawa T, Ueki A, Konishi M, Imamura A, Ishida H, Kiso M and Ando H (2017) A 1,2-trans-selective glycosyl donor bearing cyclic protection at the $\mathrm{C} 2$ and $\mathrm{C} 3$ hydroxyl groups. Eur. J. Org. Chem., 4778-4785.

Zhu X, Kawatkar S, Rao Y and Boons GJ (2006) Practical approach for the stereoselective introduction of $\beta$ -arabinofuranosides. J. Am. Chem. Soc., 128: 11948-11957. 